\title{
السمات الفنية لتابوت خشبي لسيدة من العصر الروماني
}

\section{(') (غير منشور) (1)}

أحمد عطا درباله سيف

مدرس مساعد- قسم الآتار - كلية الآداب جامعة المنيا

\section{ملخص البحث:}

التابوت يخص سيدة ثُعى من Didyme، لم بسبق نشره ومحفوظ حاليًا بالمخزن المتحفي بالبهنسا، قام الباحث بعمل دراسة وصفية للمناظر المصورة على التابوت؛ والتي كانت تُمَتل

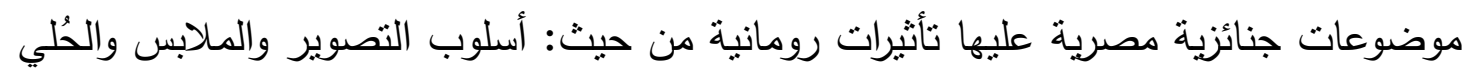

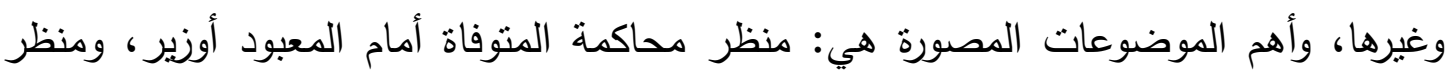

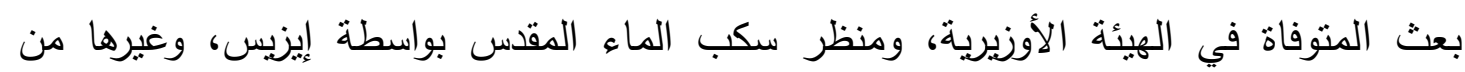

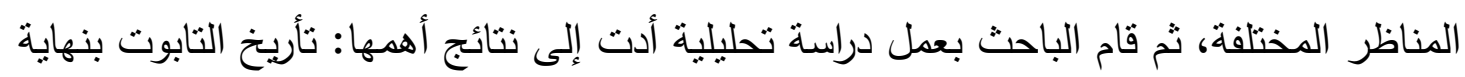

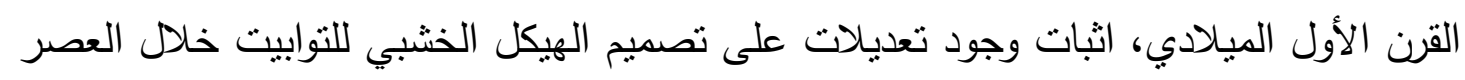

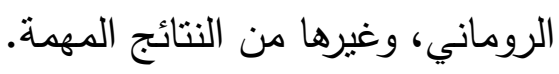

الكلمات الدالة:

$$
\begin{aligned}
& \text { r- التوابيت ذات الهيئة الآدمية } \\
& \text { 1- التوابيت الخشبية } \\
& \text { ع - محاكمة المتوفى } \\
& \text { r- مصر الرومانية }
\end{aligned}
$$

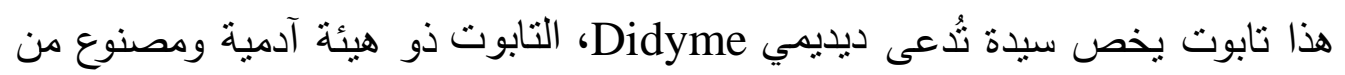
خشب الجميز، يتكون التابوت من غطاء يحتل أغلب مساحة التابوت وقاعدة صغيرة نسبياً، والمناظر منفذة على الغطاء بجوانبه الأربعة؛ اثثان طوليان واثثان قصيران عند الرأس والقدمين ألثين

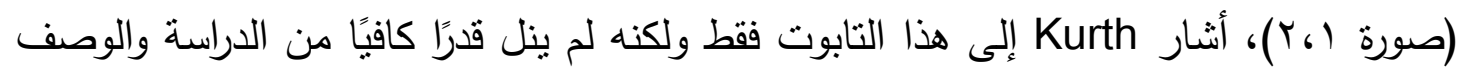

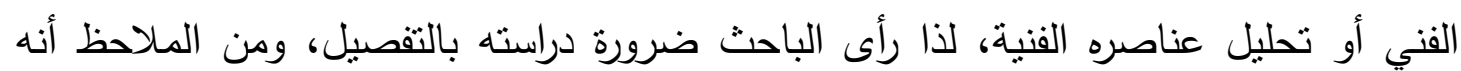

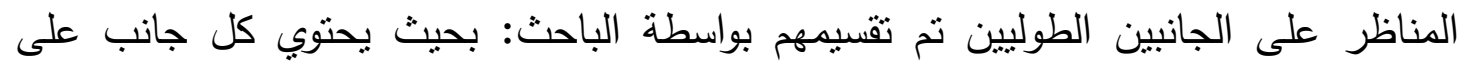

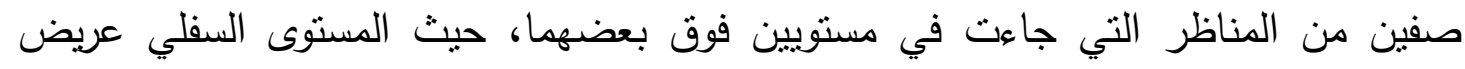

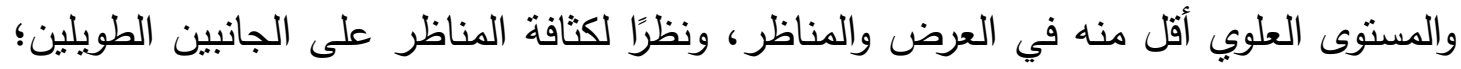
قام الباحث بتقسيم المناظر والموضوعات المصورة على التابوت بواسطة أرقام لاتينية كالتالي: -

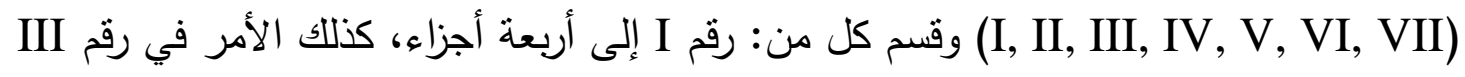


قسمه إلى أربعة أجزاء؛ وقسم رقم VII إلى ثلاثة أجزاء، أيضاً رقم V تم تقسيمه إلى ثلاثة

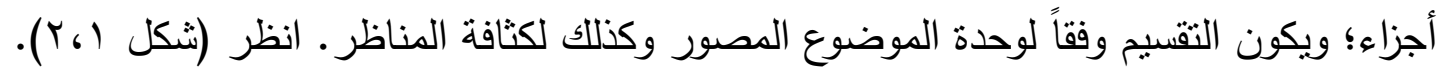
أبعاد التابوت:- أبكرن

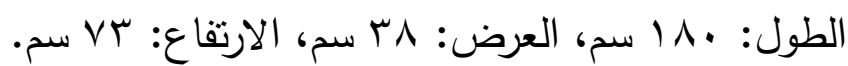

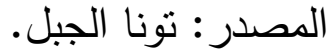

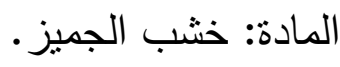
مكان الحفظ: المخزن المتحفي بالبهنسا. رقم الحفظ: 501 سجل متحف المنيا القيم. التأريخ: العصر الروماني.

اللدراسة الوصفية: الجانب الطولي الأيسر على الصف السفلي، تبدأ مناظر التابوت بمنظر رقم (I.1) (صورة r) حيث يتوسط المنظر أوزير جالساً على كرسي العرش وعلى رأسه ناج

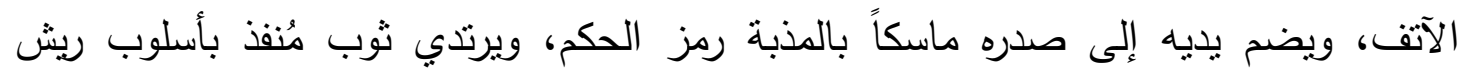
الطيور، وخلفه تقف ايزيس وترتدي ثوب يصل إلى منتصف ساقيها، وترفع يدها اليسرى تجاه

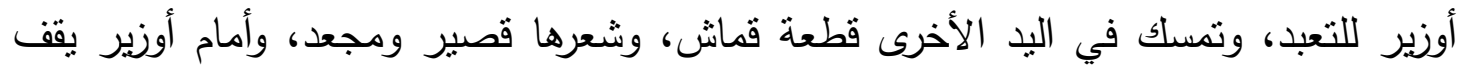

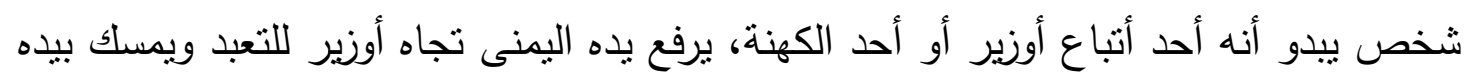

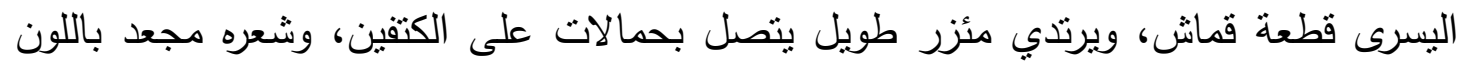

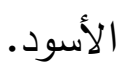

يعقبه منظر (I. 2) (صورة ؟) ويُمتل منظر أبناء حورس الأربعة بهيئة مومياوات وترتيبهم

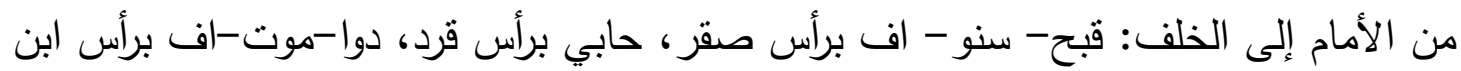

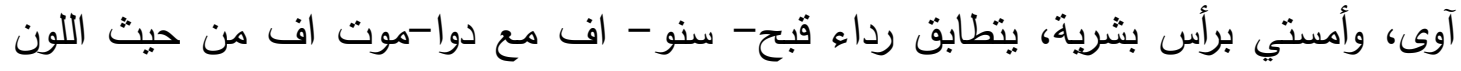
والتصميم، أما رداء أمستي وحابي منتابهان من حيث اللون ولكن مختلفان في التصميخ، فرداء

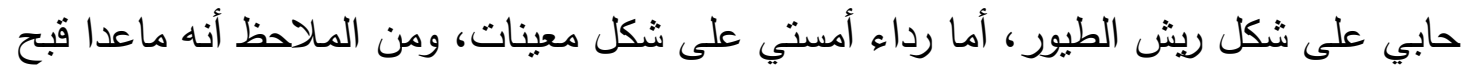

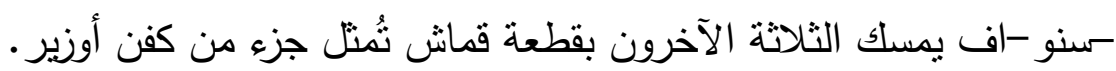

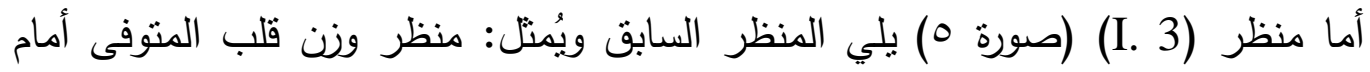

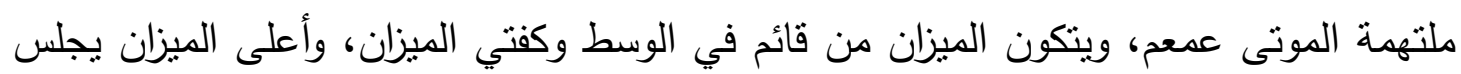

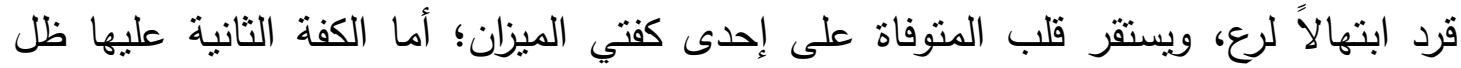

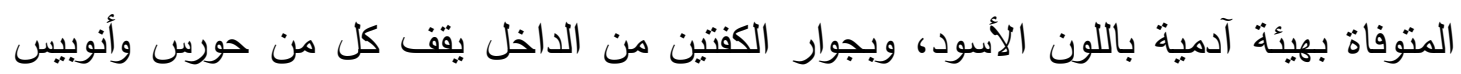

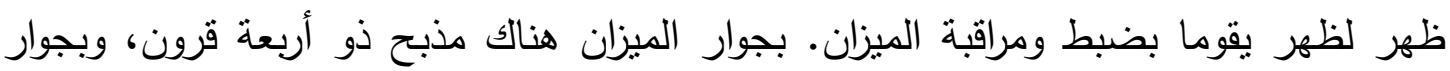


المذبح تقف ملتهمة الموتى أعلى قاعدة نتبه المقصورة، أما ملتهمة الموتى نظهر بهيئة أسد، يتدلى لسانها خارج فمها، وهناك سكين أمامها أسفل القدمين. ثم منظر (I. 4) (صورة 7) يلي منظر وزن القلب مشهد المتوفاة تقف في المنتصف ويحيط بها اثثان من السيدات النادبات يُمثلان ايزيس ونفتيس، تقف المنوفاة ذراعيها مفرودنان بجوار بجسدها، وترتدي ثوب ذي حمالتين على الكتقين، ويصل إلى منتصف ساقيها وبه اثتان من العناصر الزخرفية Calvi، أما ايزيس ونفتيس تظهران بهيئة الندابتين ترفع كل منهما يديها تجاه وجهها، ويرتديان ثوب مشابه من حيث التصميم لثوب المتوفاة، ولكن يختلف في الألوان والزخارف، ويليهما واجهة مقصورة أو مدخل مقبرة تتطابق من حيث التصميم والألوان مع المذبح لتوبح

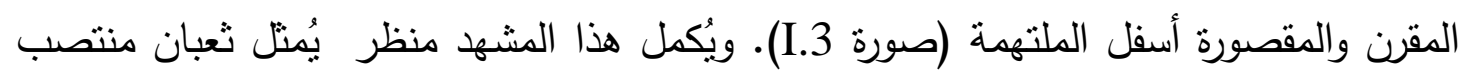

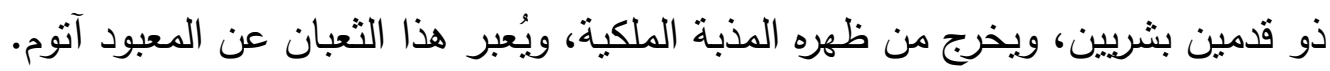
يعلوه السجل العلوي منظر II (صورة V): ويُمتل شريط أفقي أقل من حيث السُمك، والمناظر

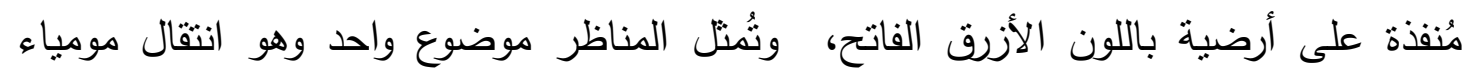
المتوفاة من مقبرتها في المركب الليلية في العالم السفلي في حراسة الجن الحامية، من اليمين

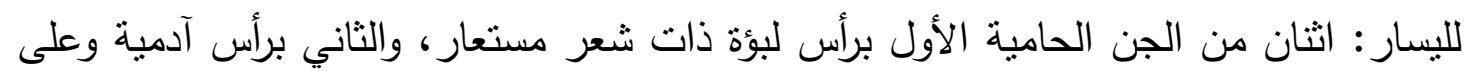

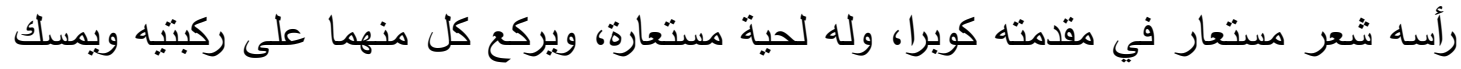

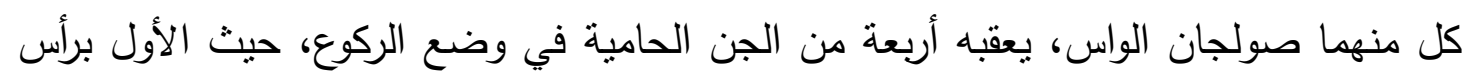

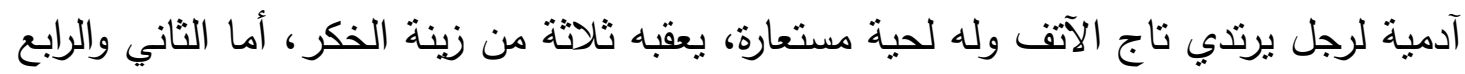

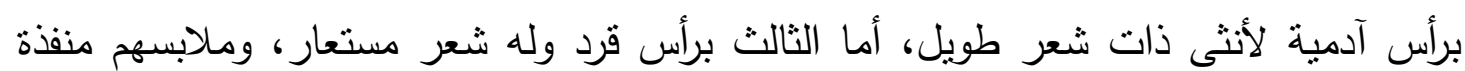

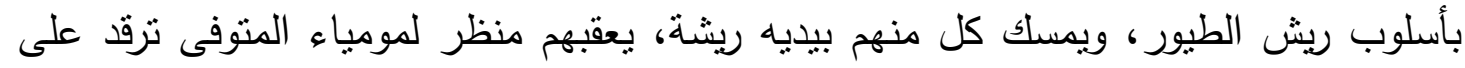

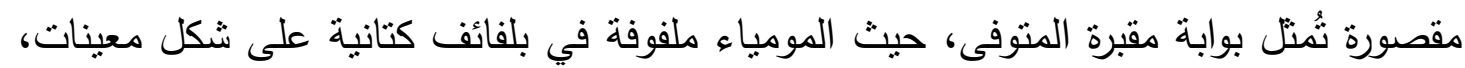

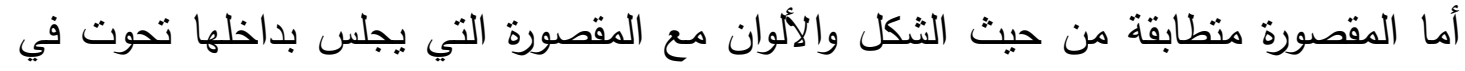
منظر (V.2)، يعقب هذا المنظر اثنان من الجن الحامية برأس آدمية لأنثى، يركع كل منهما

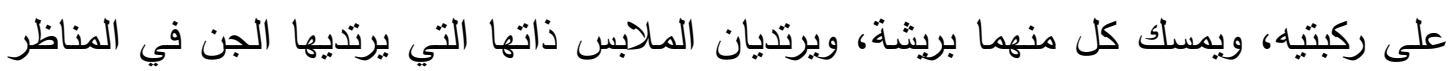
السابقة، والهدف من وجودهم هو حماية المركب الذي ينقل مومياء المتوفى في العالم السفلي، حيث يعقبهم منظر لمركب ذو مجداف في مؤخرته، ومقدمة ومؤخرة المركب على شكل البردي المفتوح يعلوه قرص الثمس، ويسنقر أعلاها مومياء تحيط به لفائف كتانية. 
منظر (III.1) (صورة ^): يُمُنل سيدة برأس بقرة وترتدي ثوب ضيق يصل إلى منتصف

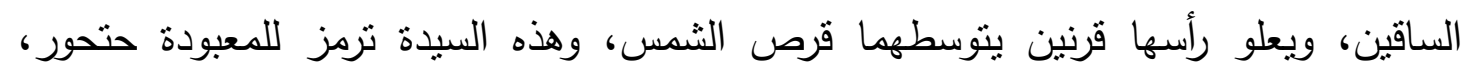

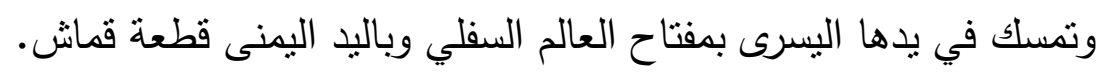

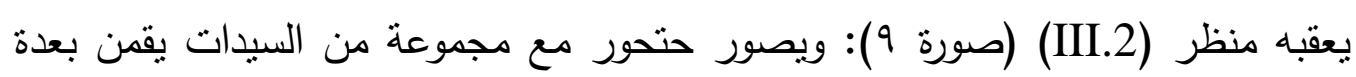
أدوار مختلفة، من الأمام إلى الخلف: سيدة بهيئة آدمية كاملة تقوم بتسجيل اسم المتوفاة داخل

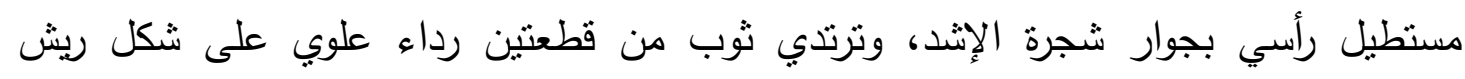

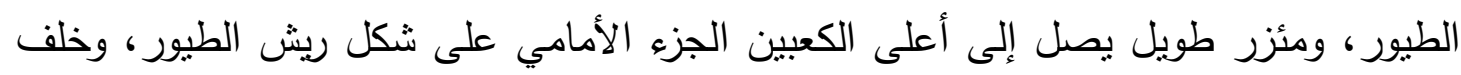

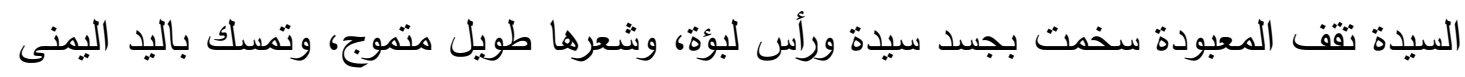

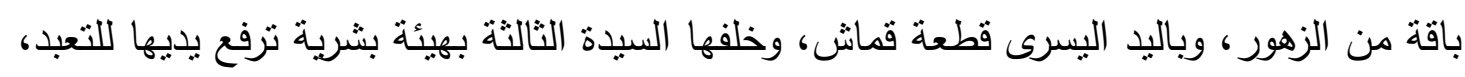

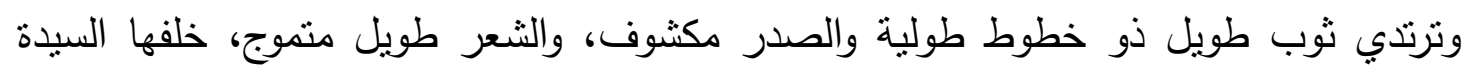

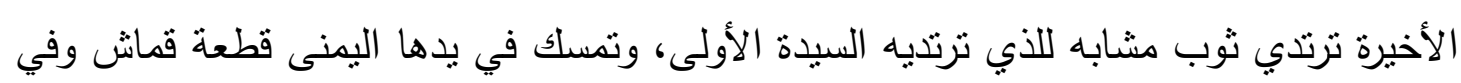
اليد اليسرى إناء مستدير صغير تقدمه كقربان، وترتدي شعر مستعار قصير .

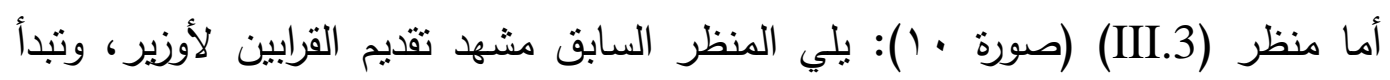
بمائدة قرابين لها ستة قوائم يظهر منهم ثلاثة فقط على شكل زهرة لونس مفتوحة؛ وأسفل مائدة

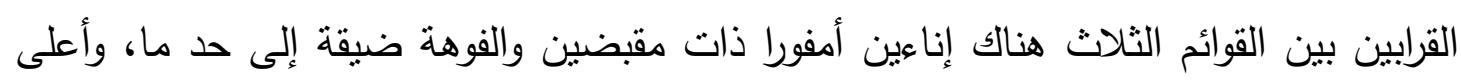

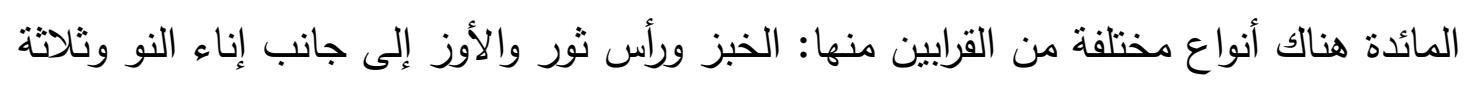

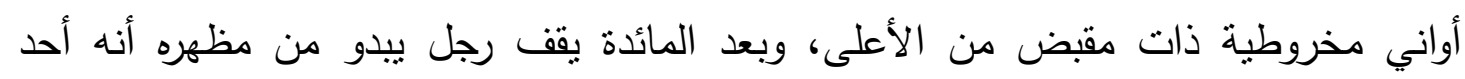

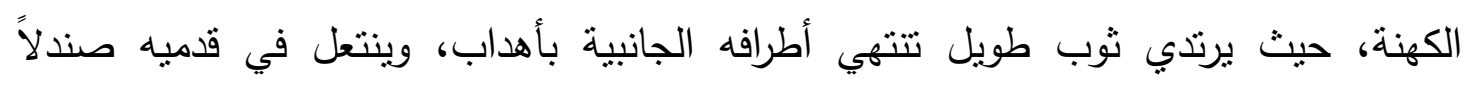

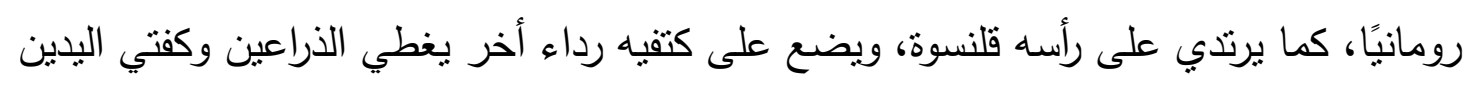

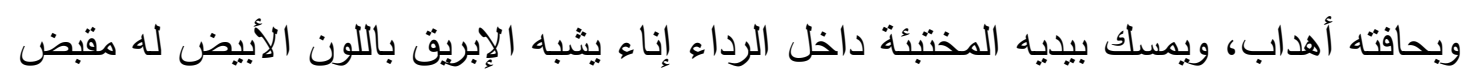

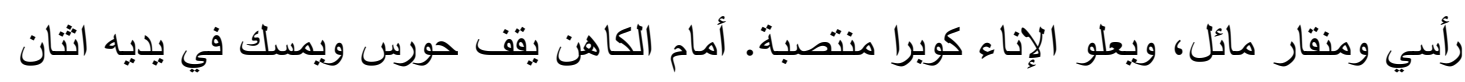
من إناء النو يقدمه لأوزير، ويتطابق الرداء الخاص به مع الإناء كعار السيدة الأخيرة في منظر (III.2)،

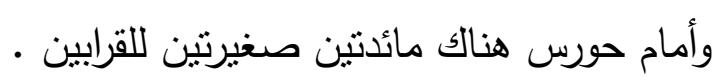
منظر (III.4) (صورة (1) (1): يوصف هذا المنظر تقديم المتوفاة إلى أوزير بواسطة أنوبيس، حيث يجلس أوزير على عرشه ويمسك المذبة بيديه، يتثابه من حيث الهيئة والملابس مع نظيره

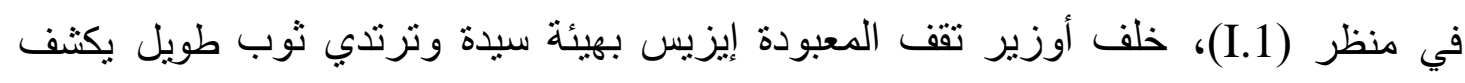

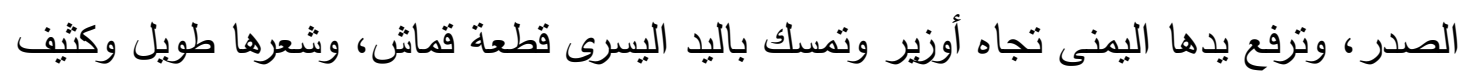

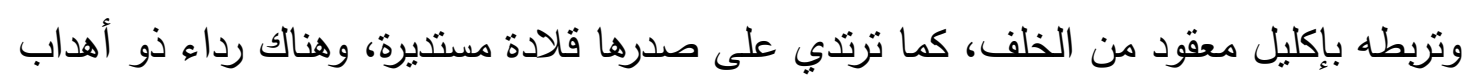


على ظهرها. أمام أوزير تقف المتوفاة ترتني ثوب طويل يكثف احد الثذيين وهناك وشاح يغطي الجزء العلوي لجسدها، ويوجد اثثين من الأشرطة الزخرفية Calvi بطول الرداء، وشعرها طويل بكايل

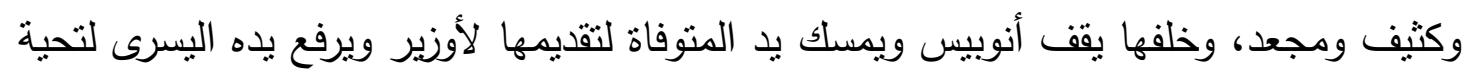

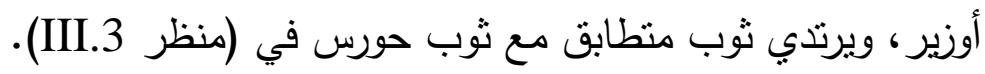

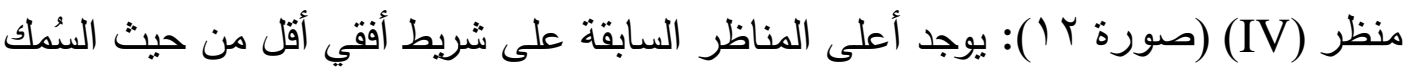

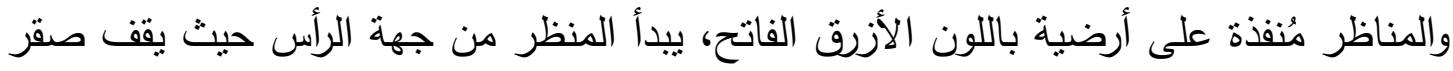

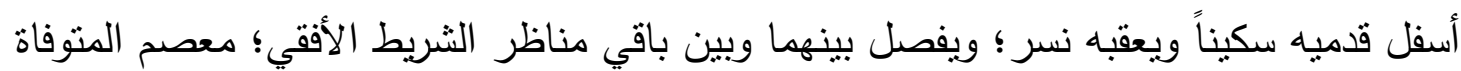

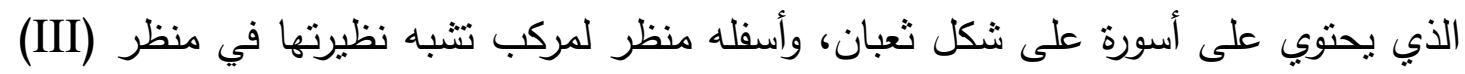

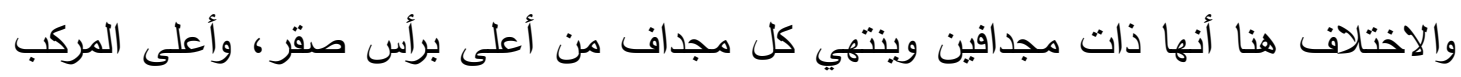

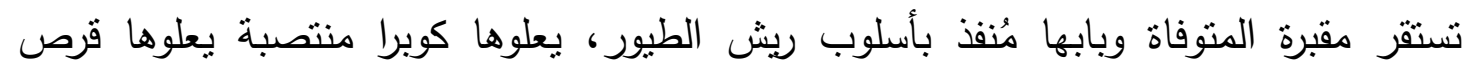

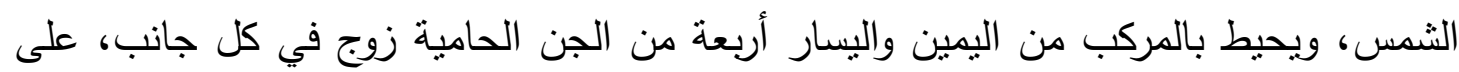
اليمين اثثان من الجن برأس ثعبان الأول له شعر كثيف طويل، والأخر بشعر مستعار ، ولكل

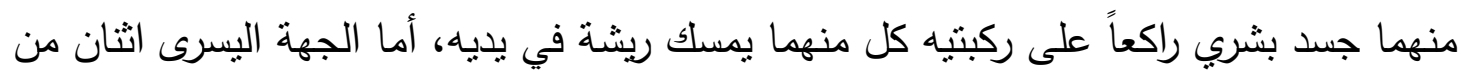

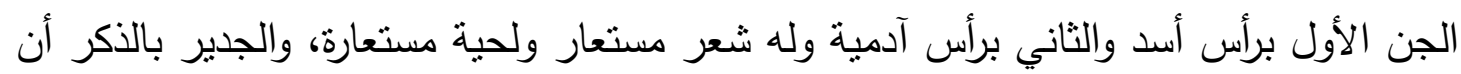

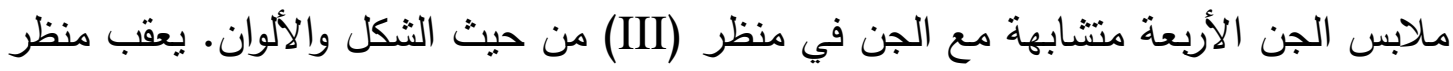

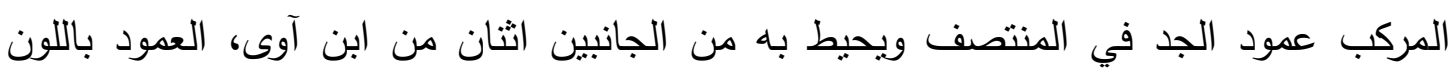

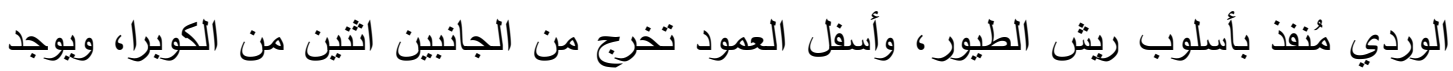

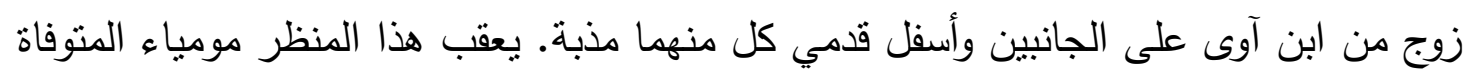

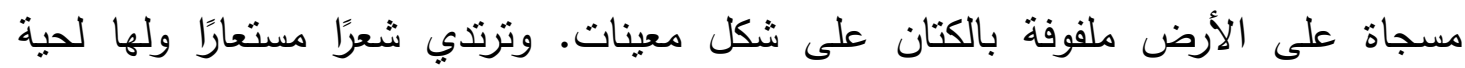
مستعارة، يعلوها قرص شمس له جناحان يخفقان يتدلي من القرص كوبرا.

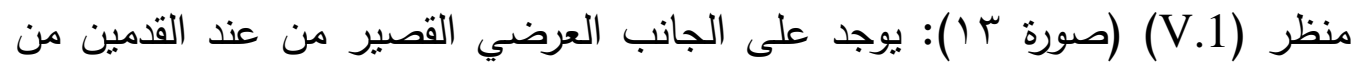

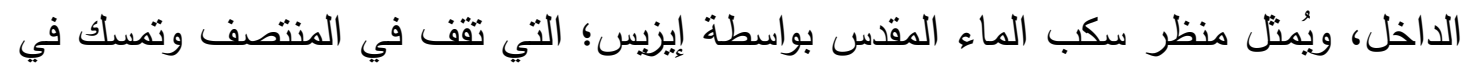
كل بد إناء الحست وتسكب بواسطته الماء المقس على اثثين من طيور البا على الجانبين أسفل

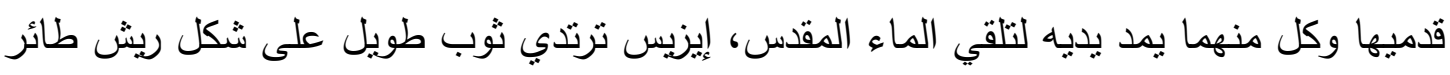

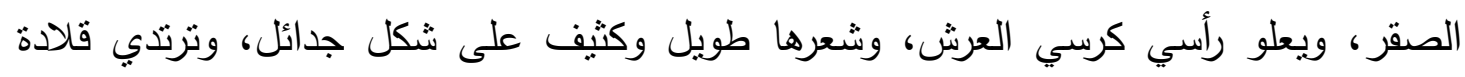

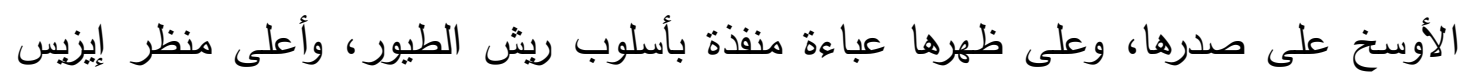

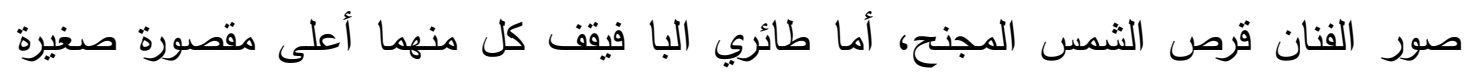

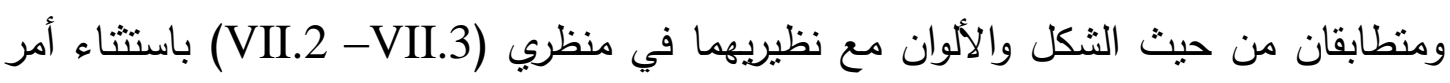


وحيد وهو أن الفنان صور أعلى رأس كل منهما ناج الوجه القبلي. وأسفل إيزيس صور الفنان بالنحت البارز قدمي المتوفاة ، وترتدي صندلاً رومانيًا.

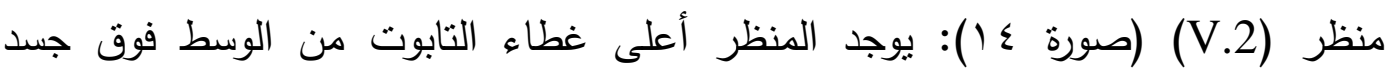

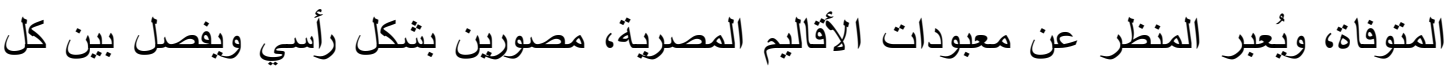

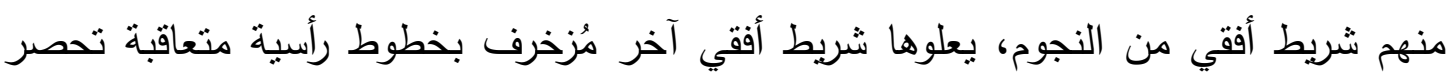

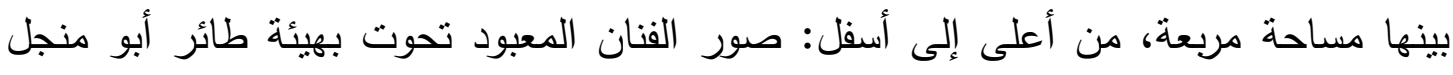

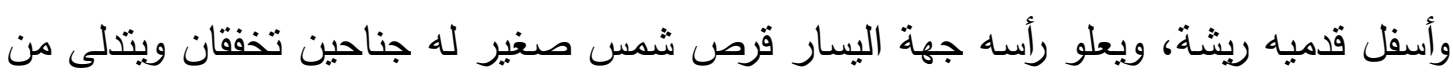

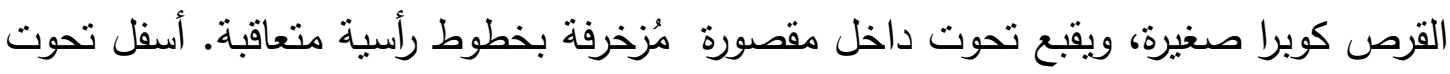

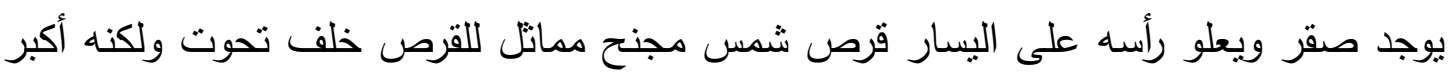
حجماً، وأسفل قدمي الصقر هناك علامة عنخ. أسفل الصقر يوجد قرد البابون رابضاً وعلى رأسه البهار

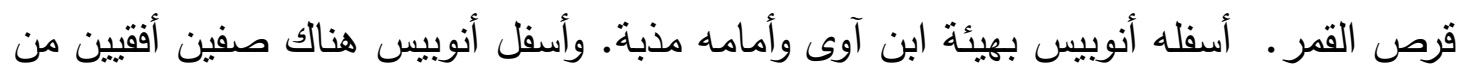

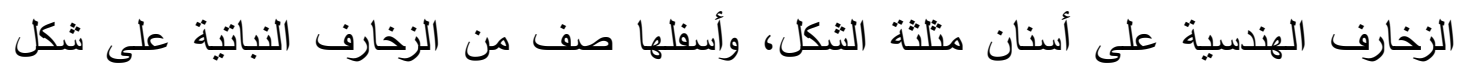

منظر (V.3) (صورة 0 (1): ويُ3تل الجزء العلوي لغطاء التابوت حيث يوجد صدر ووجه المتوفاة، من الملاحظ أن رأس المنوفاة مرفوع قليلاً إلى أعلى ربما يدل على على فكرة البعث، وقد

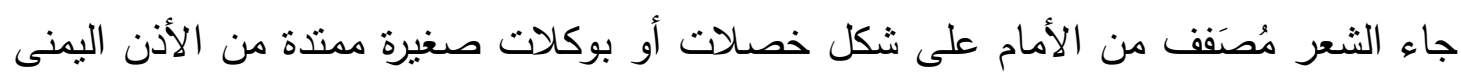

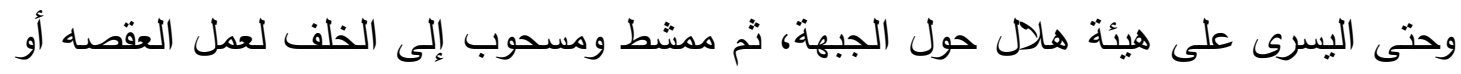

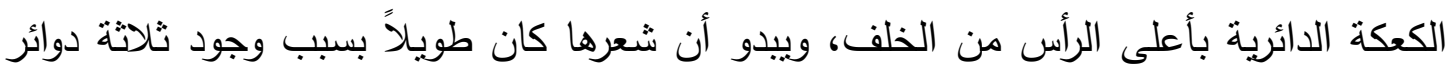

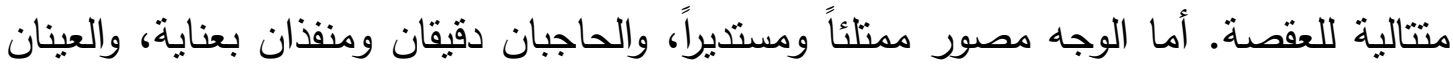

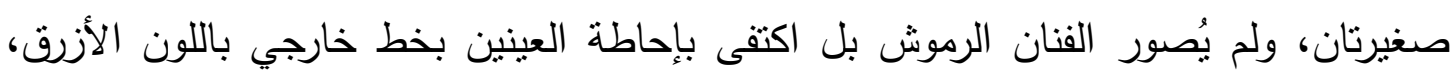

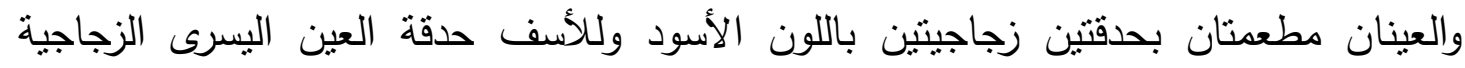

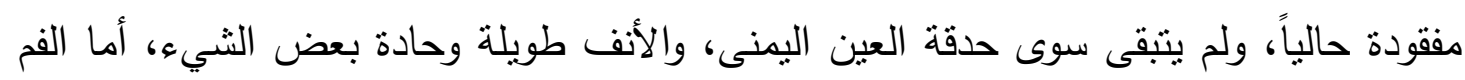
دقيق وصغير الحجم، والأذنين كبيرتان وتختفي أسفل بوكلات الثعر وكل أذن مزينة بقرط ذهبي لئي مستخير الرداء: ترتدي المتوفاة ثوب هيماتيون طويل باللون الأرجواني يصل إلى القدمين؛ يتخلله اثنان

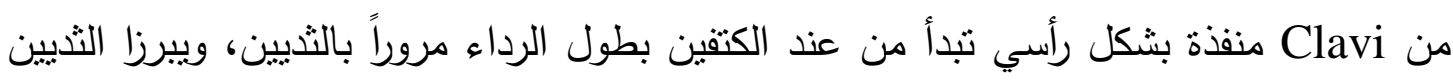

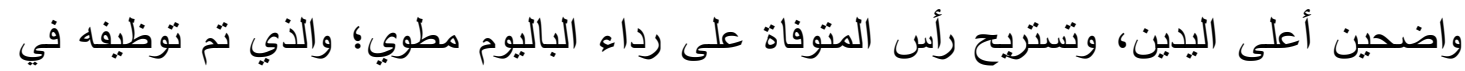


المنظر كوسادة تحت رأسها، ويظهر بجوار رأسها على الجانبين علامة Gammadia وهي علامة زخرفية توجد عادة في رداء الباليوم الروماني. العلي والزينة: ترندي المنوفاة قلادة طويلة تمند إلى أسفل ثدييها؛ تتكون من قطع مستطيلة

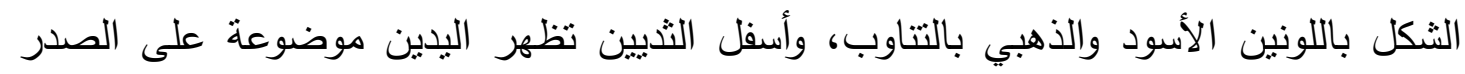

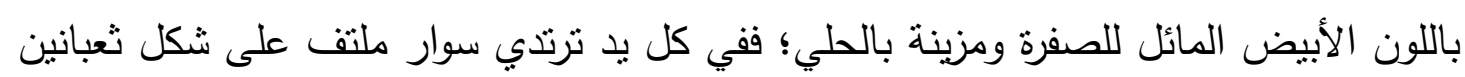

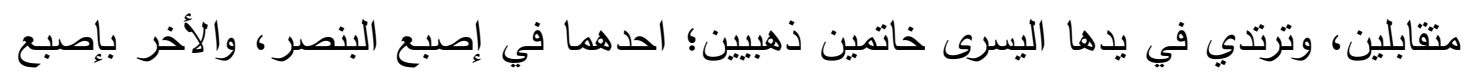

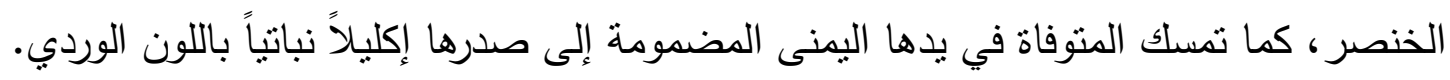
منظر (VI): ويوجد على الجانب العرضي القصير، عند القدمين من الخارج، حيث الجزء

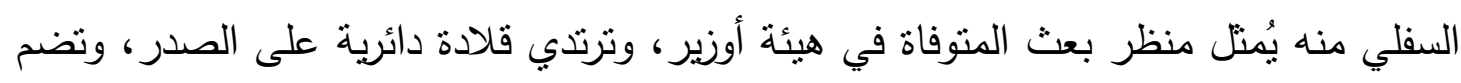

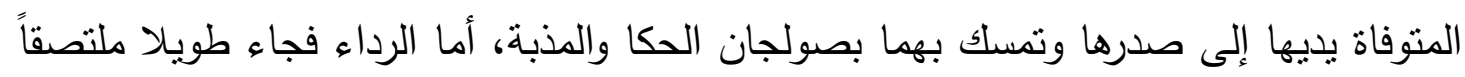
بالجسد يصل إلى القدمين، مُنفذ بأسلوب ريش طيور ، ويحيط بالرداء من الجانبين عباءة باللون

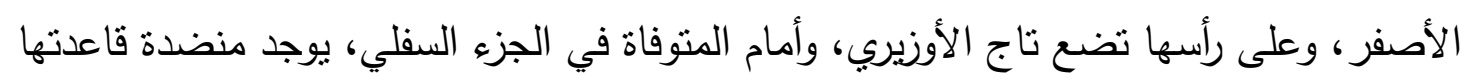

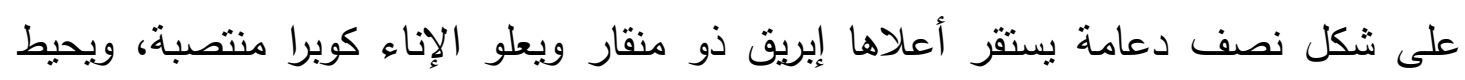

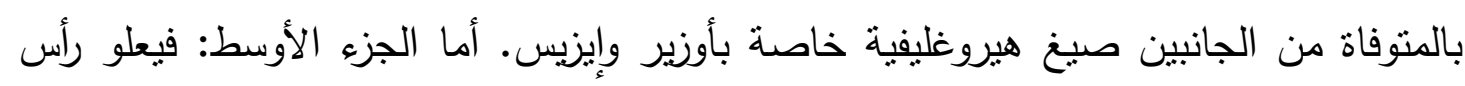
المتوفاة وهي خطوط أفقية؛ تحصر بينها مساحة مسنطيلة مدون عليها اسم المتوفاة باللغة اليونانية، (ديديمي المسماة ثاتريس ابنة فيلبيون)

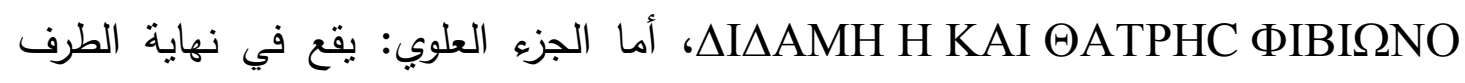
العلوي للمنظر ؛ حيث يستقر قرص الثمس المجنح، ويخرج من قرص الثمس اثثان من الكوبرا

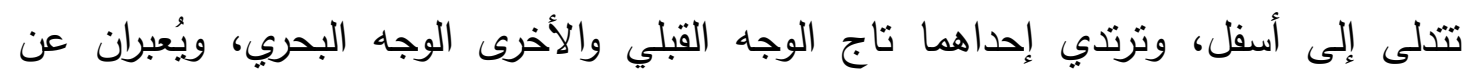
المعبودنين نخبت وواجيت. منظر (VII.1) (صورة V V) (I) يوجد على الجانب العرضي القصير خلف رأس المتوفاة مباشرة ويُمتل منظران رأسيين: العلوي جعران مجنح يعلوه قرص الثمس؛ وأسفله منظر للمعبودة

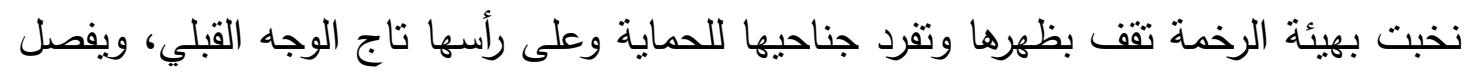
بين الجعران والرخمة صف أفقي من الكتابة الهيروغليفية. منظر (VII.2) (صورة ^1): يوجد على يسار المنظر السابق وأعلى الكتق الأيسر

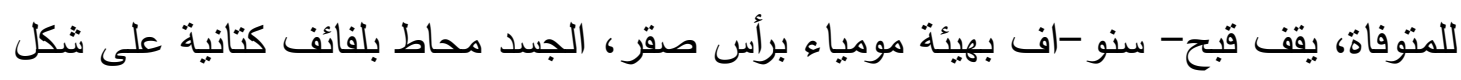

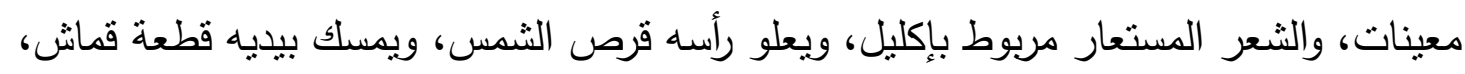

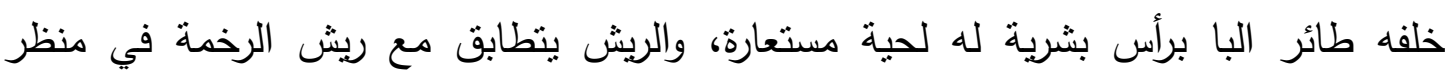


(VII.1) والثعر قصير ومربوط بإكليل، ويعلو رأسه قرص الثمس، ويفرد جناحيه إلى الأمام للحماية .

أما منظر (VII.3) (صورة 9 (1) ) يوجد على اليمين حيث يعلو الكتف الأيمن للمتوفاة،

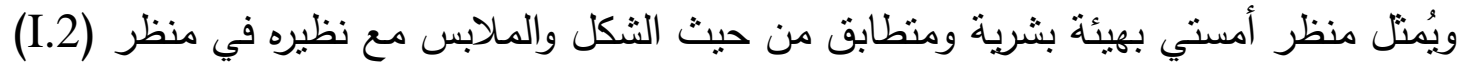

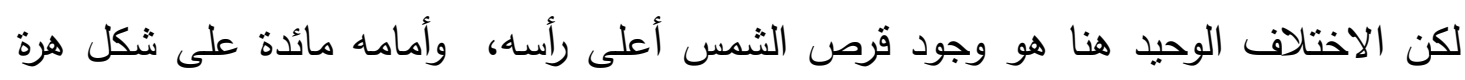

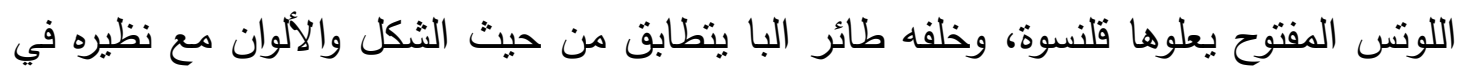

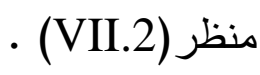

\section{تحليل لأبرز مناظر التابوت}

الجدير بالملاحظة أن مناظر الأثخاص المصورة على التابوت كان لها ارتباط وثيق ونيق

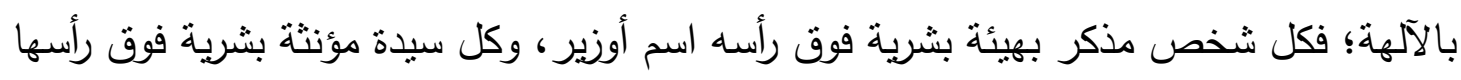

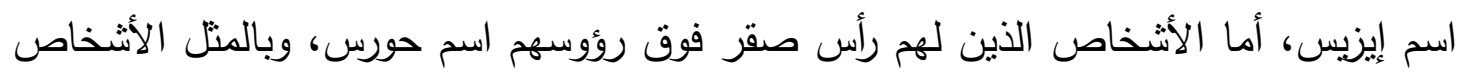

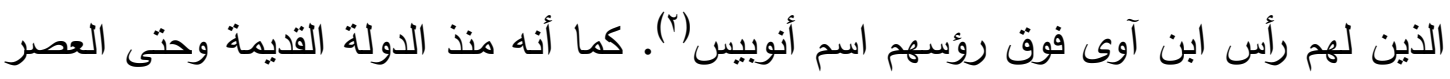

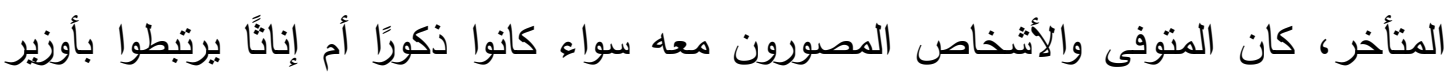

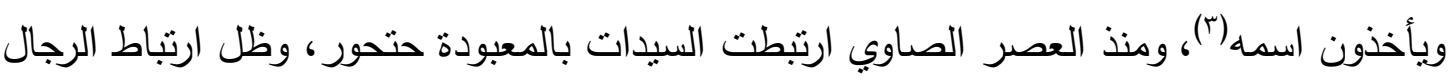

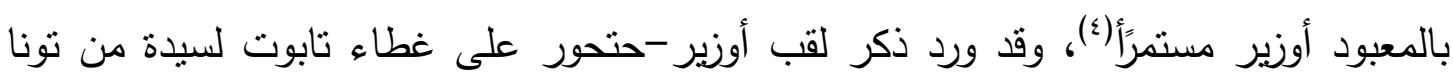

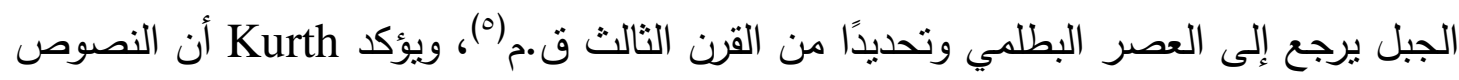

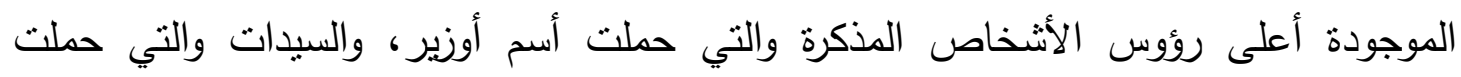

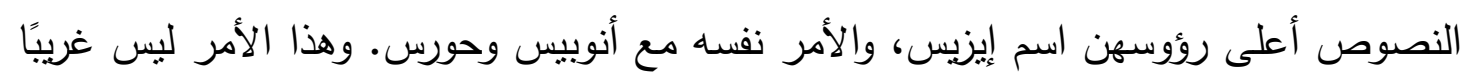

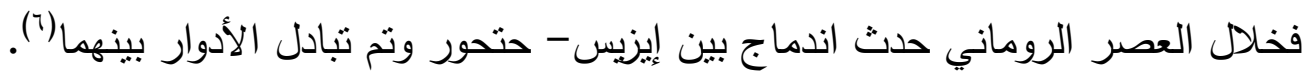

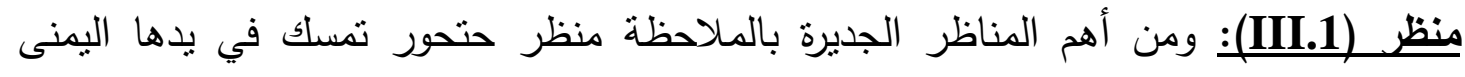

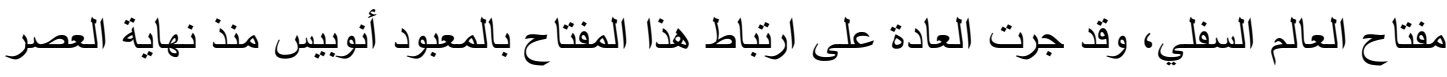

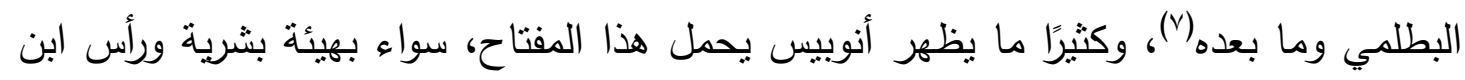

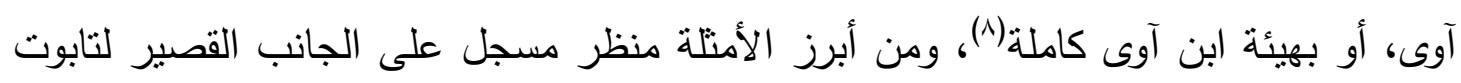

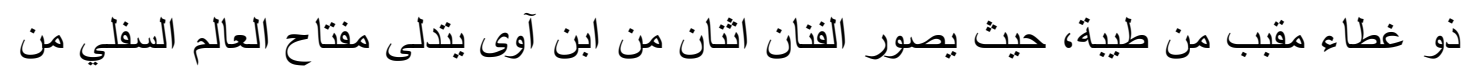

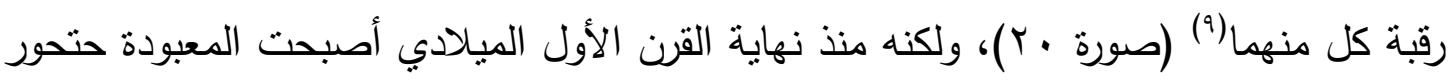

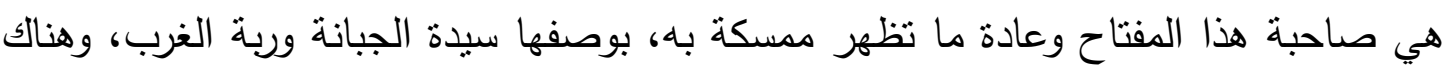

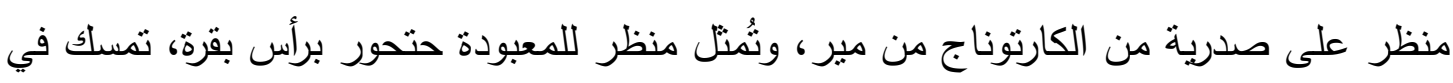

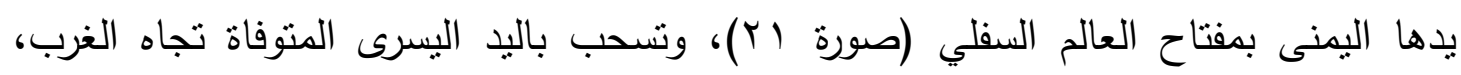


وأمامها المعبود جب يسكب الماء من إناء الحست، وأمامه المعبودة نفتيس تمسك بالقماش

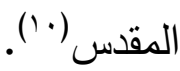

منظر (VII.1): هذا المنظر بوجد خلف رأس المنوفاة؛ ويُمنل منظران رأسيان العلوي هو

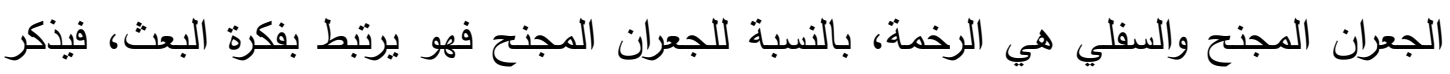
Assmann

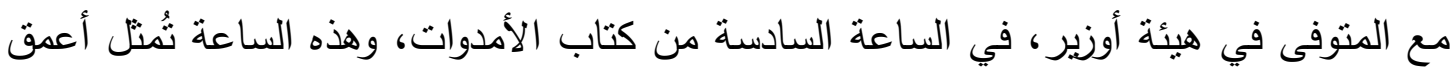

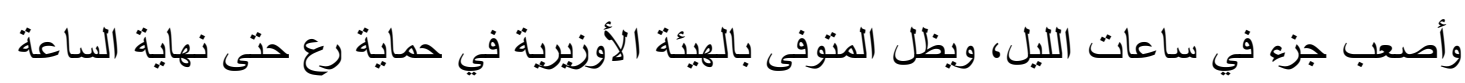

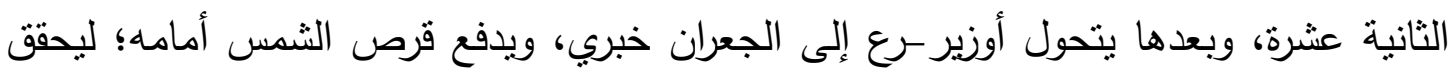

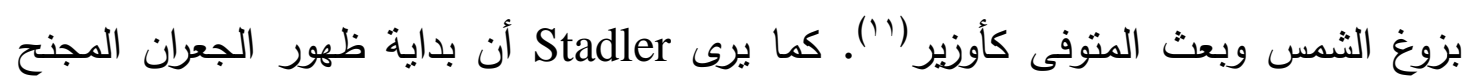

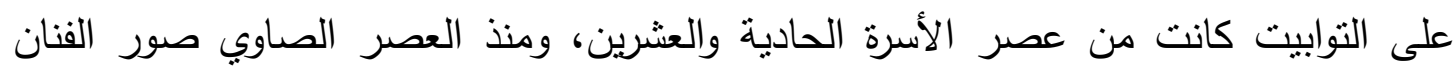

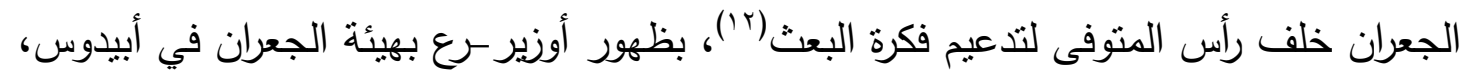

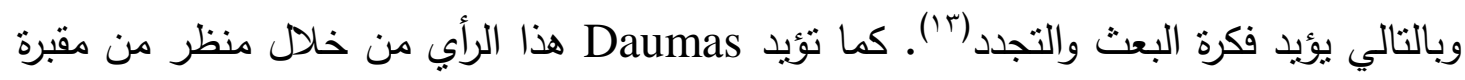

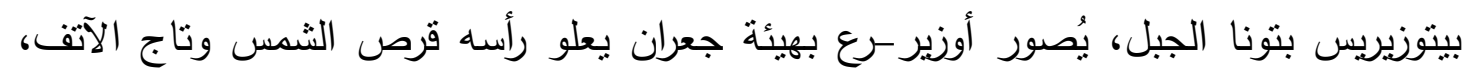

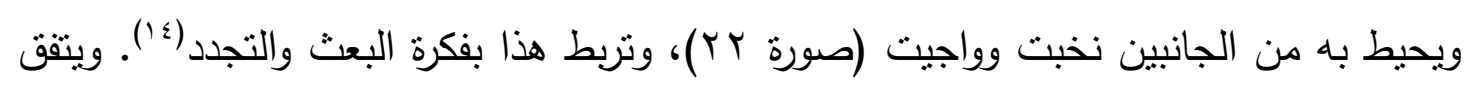

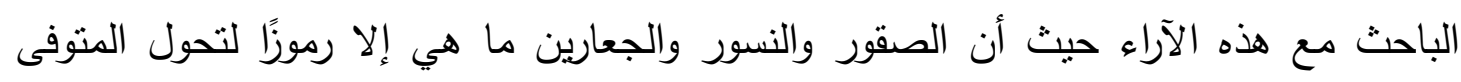

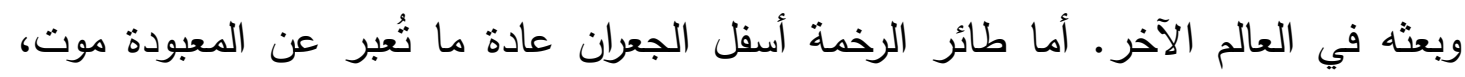

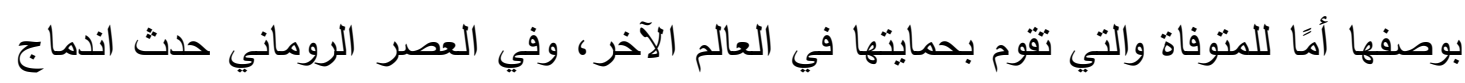
ما بين المعبودات موت-إيزيس- نخبت، فأصبح طائر الرخمة رمز للاندماج الجديد (10).

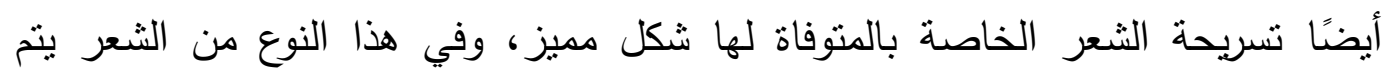

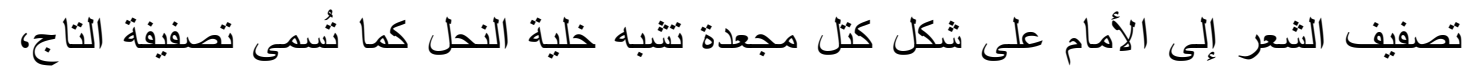

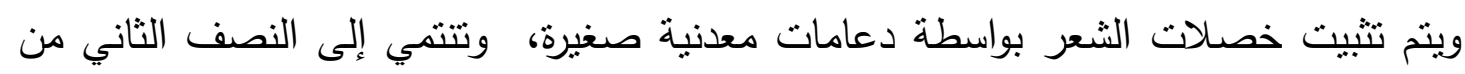

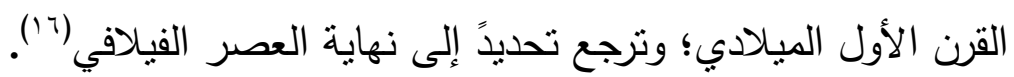

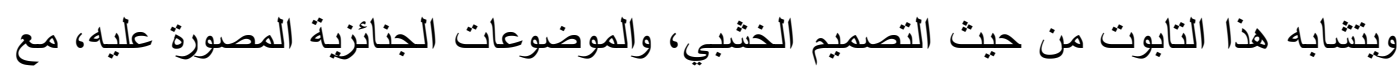

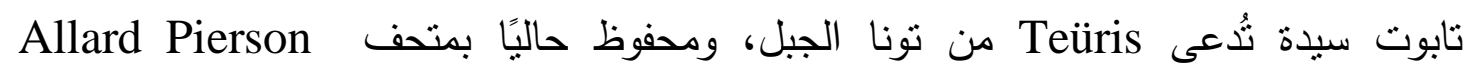

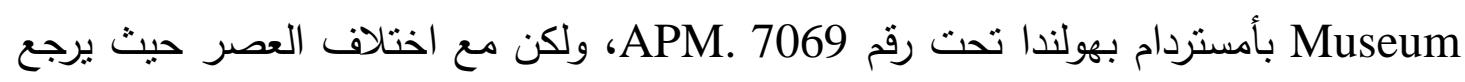

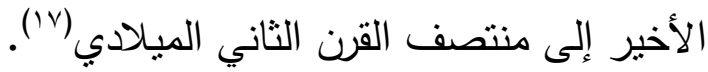




\section{نتائج البحث}

- يرجع تأريخ هذا التابوت إلى الربع الأخير من القرن الأول الميلادي، وفقًا للأسلوب

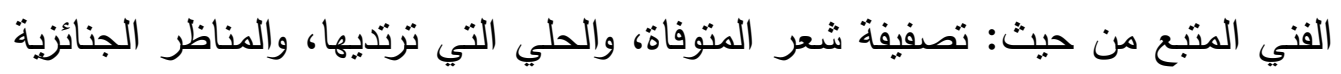

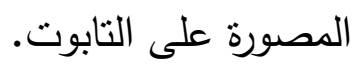
- - تميز التصميم الخشبي للتابوت بأن الغطاء بحتل أغلب حجم التابوت؛ وأصبحت القاعدة

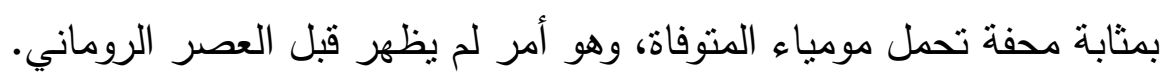

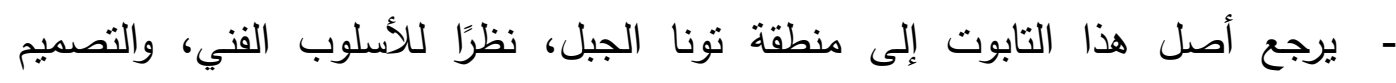

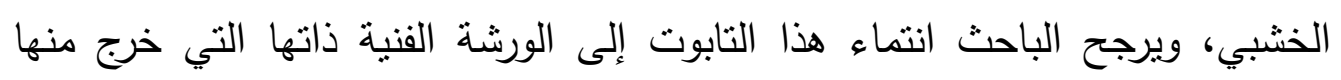
نابوت Teüris - - بعث المنوفاة في الهيئة الأوزيرية بكامل تفاصيلها الأنثوية؛ يُعد من الأمور المميزة للفن

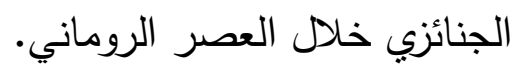

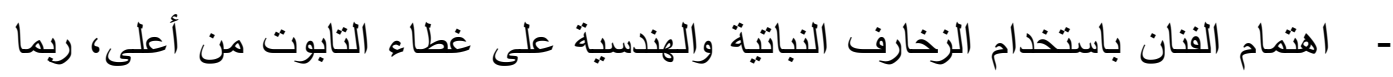

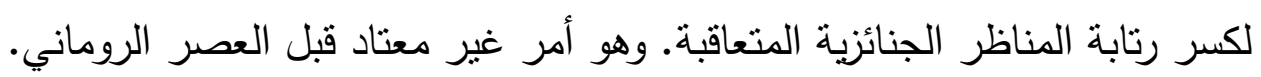

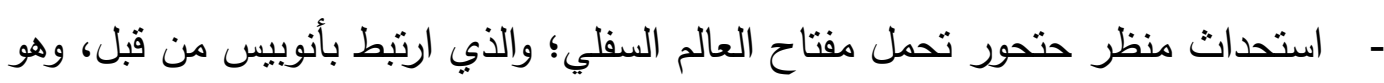
أمر لم يظهر قبل القرن الأول الميلادي. - كتابة اسم المتوفاة أعلى منظرها (VI) باللغة اليونانية، وهو أمر فريد من نوعه لم يتكرر قبل العصر الروماني. 


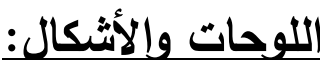

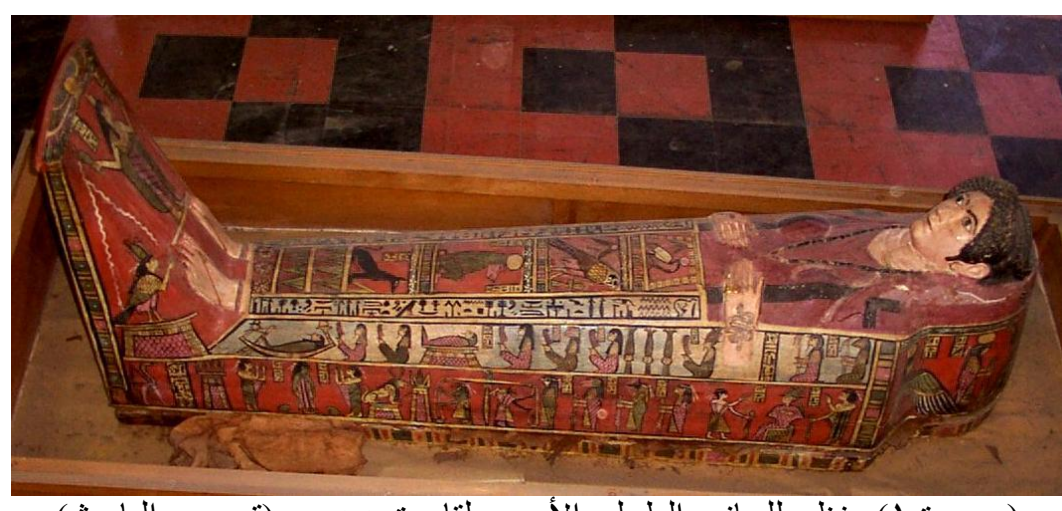

(صورة ( ) منظر للجانب الطولي الأيسر - لتابوت ديديمي (تصوير الباحث)

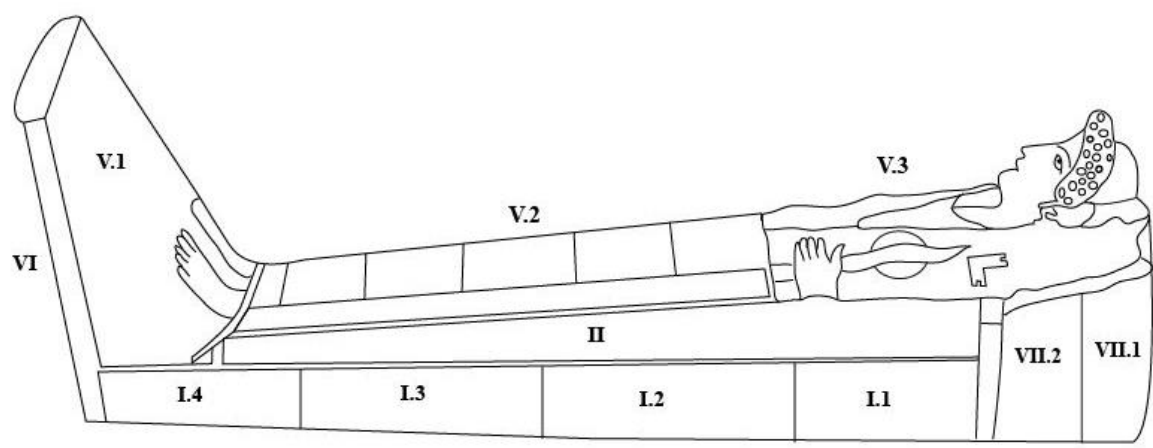

(شكل ( ) الجانب الطولي الأيسر - لتابوت ديديمي (تصميم و عمل الباحث)

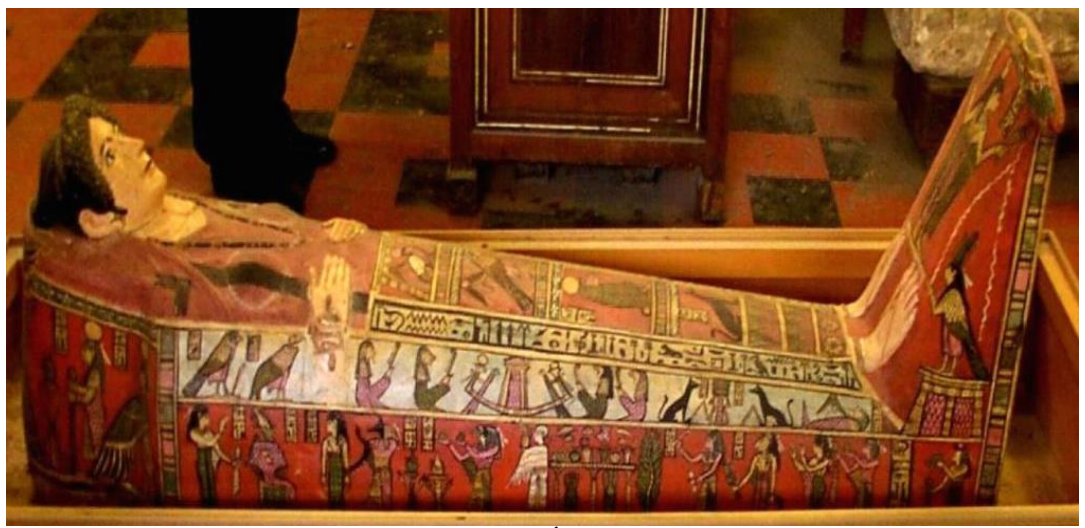

(صورة ؟) منظر للجانب الطولي الأيمنـ لتابوت ديديمي (تصوير الباحث)

r. 


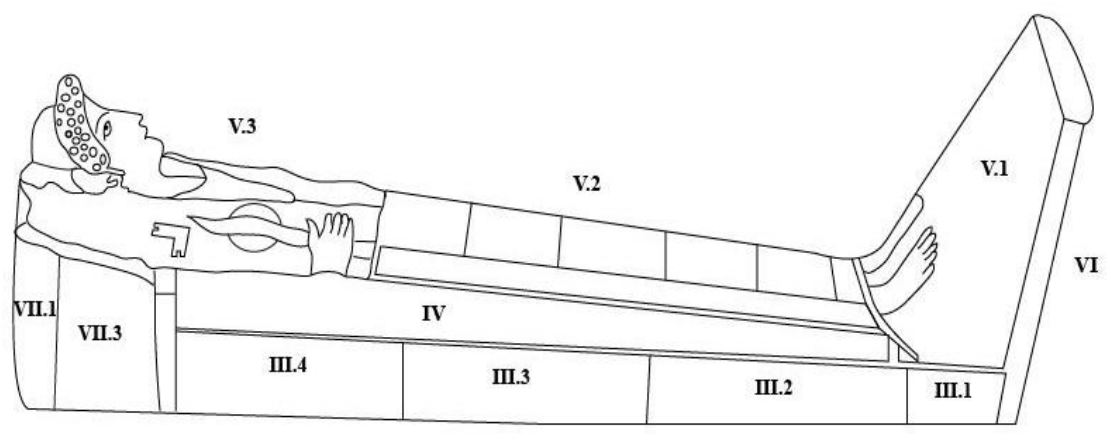

(شكل Y ) الجانب الطولي الأيسر ـ لتابوت ديديمي (تصميم و عمل الباحث)
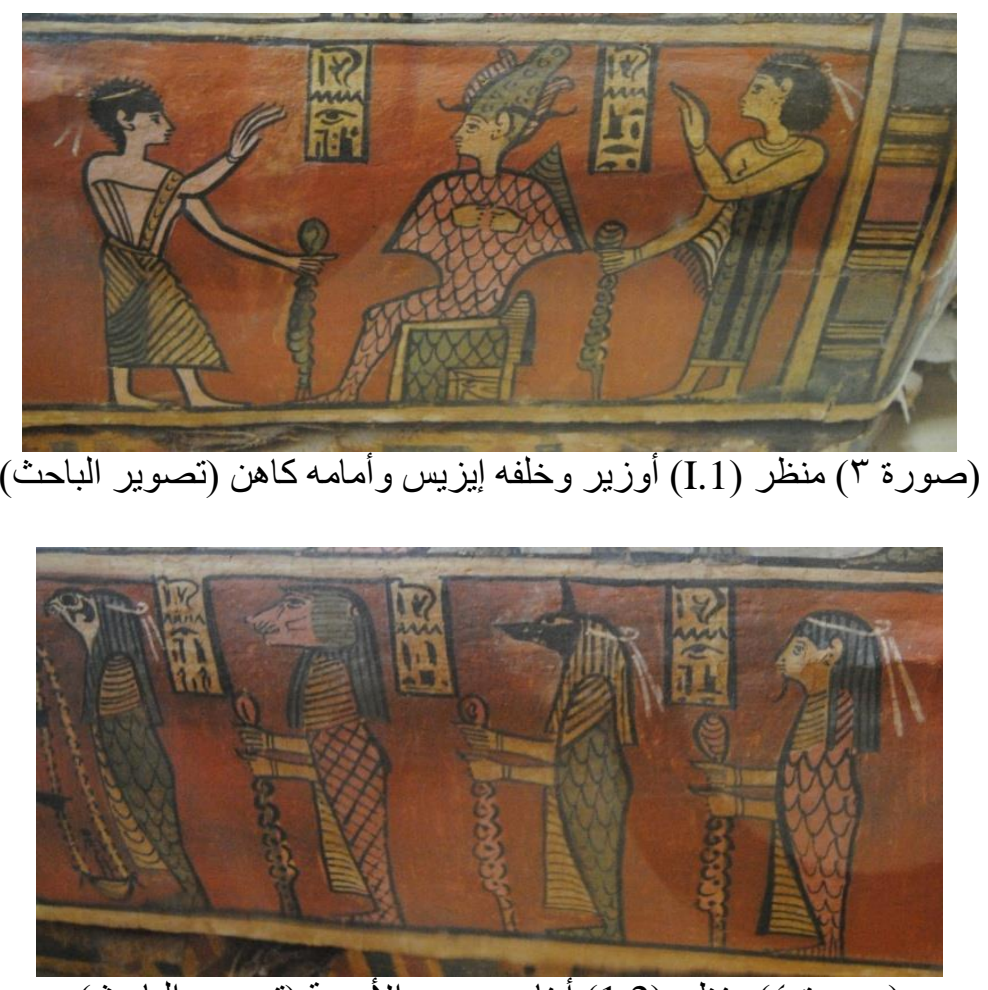

(صورة ؟) منظر (1.2) أبناء حورس الأربعة (تصوير الباحث)

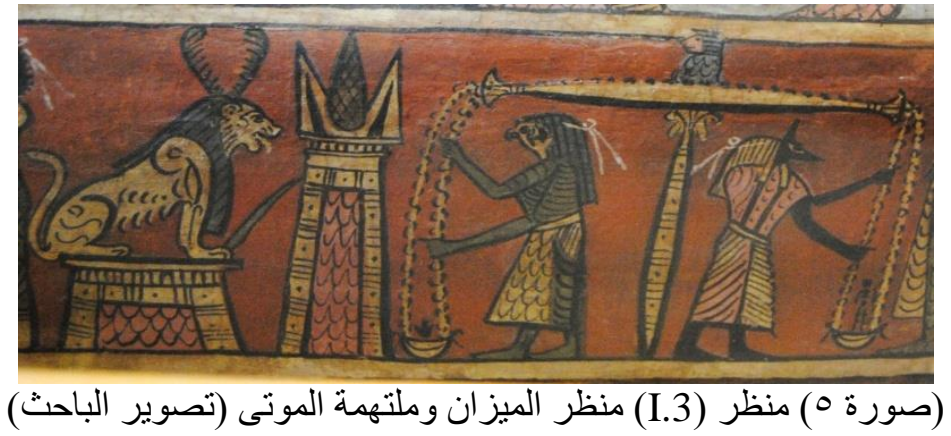




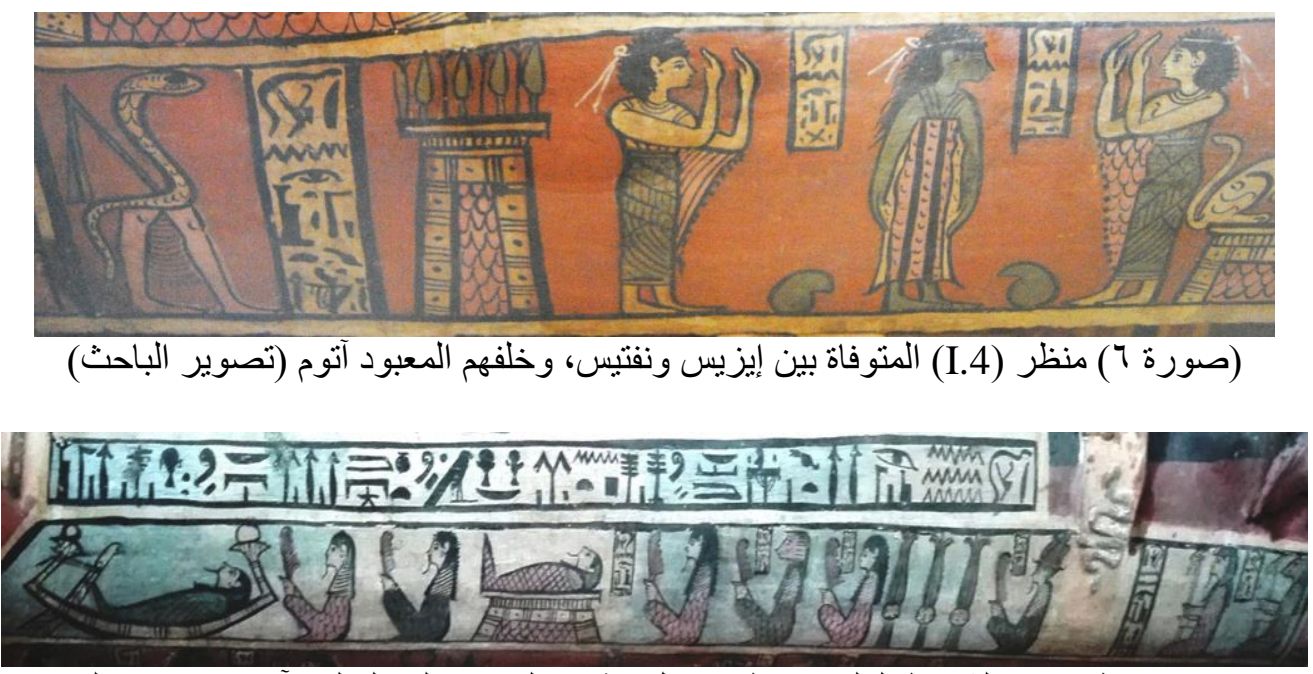

(صورة V) منظر (III) الشريط العلوي منظر انتقال جثمان المنوفاة إلى العالم الآخر (تصوير الباحث)

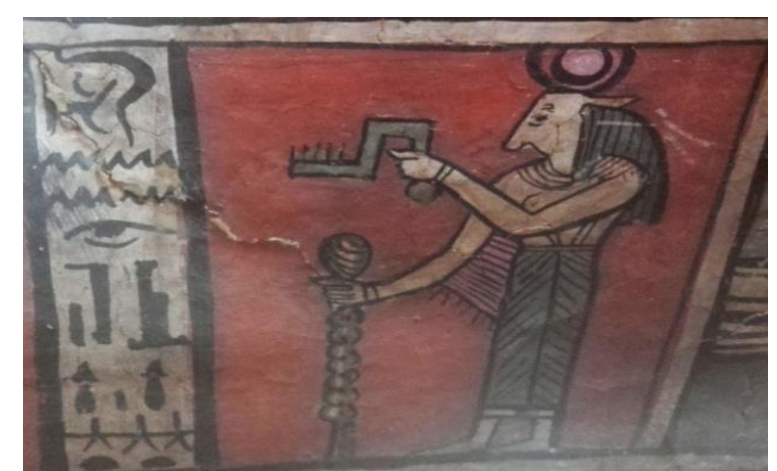

(صورة ^) منظر (III.1) منظر حتحور تحمل مفتاح العالم السفلي (تصوير الباحث)
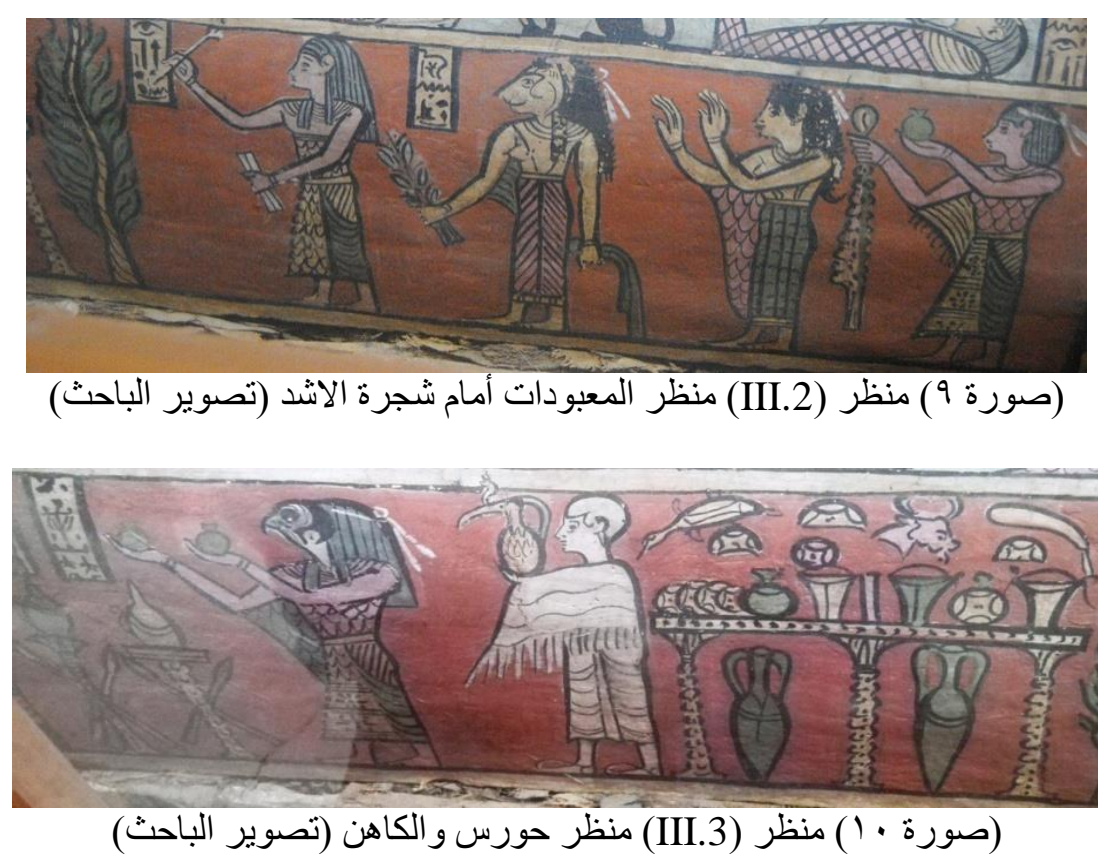


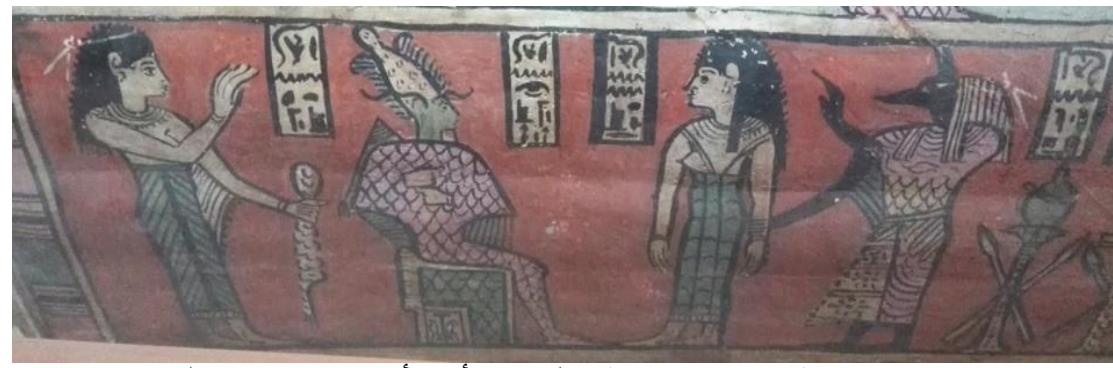

(صورة I (1II.4) منظر (III) منظر المنوفاة أمام أوزير (تصوير الباحث)

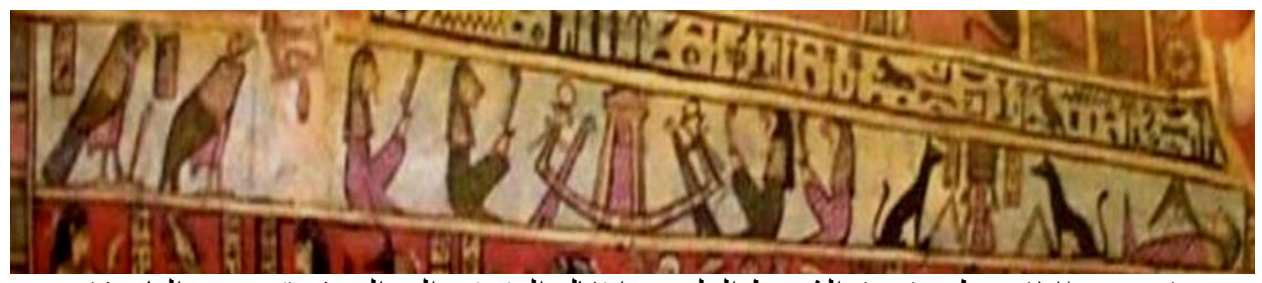

(صورة Y Y ) منظر (IV) الثريط العلوي- انتقال المتوفى إلى البعث (تصوير الباحث)

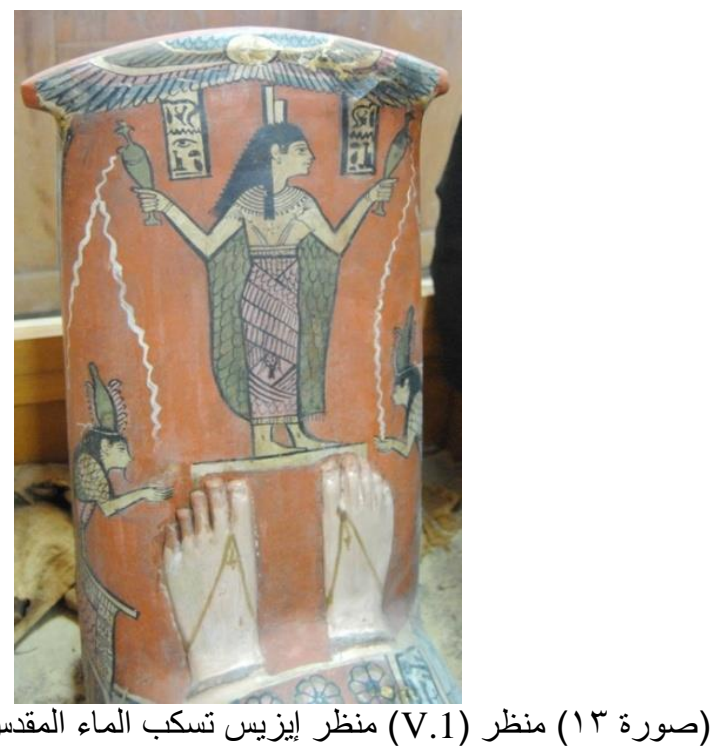

(صورة ז ا ) منظر (V.1) منظر إيزيس تسكب الماء المقس (تصوير الباحث)

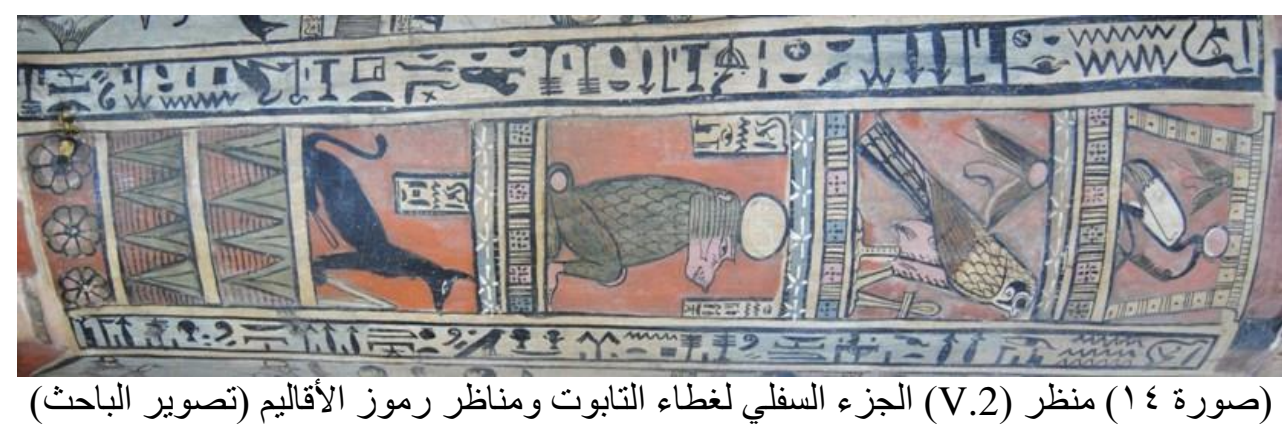



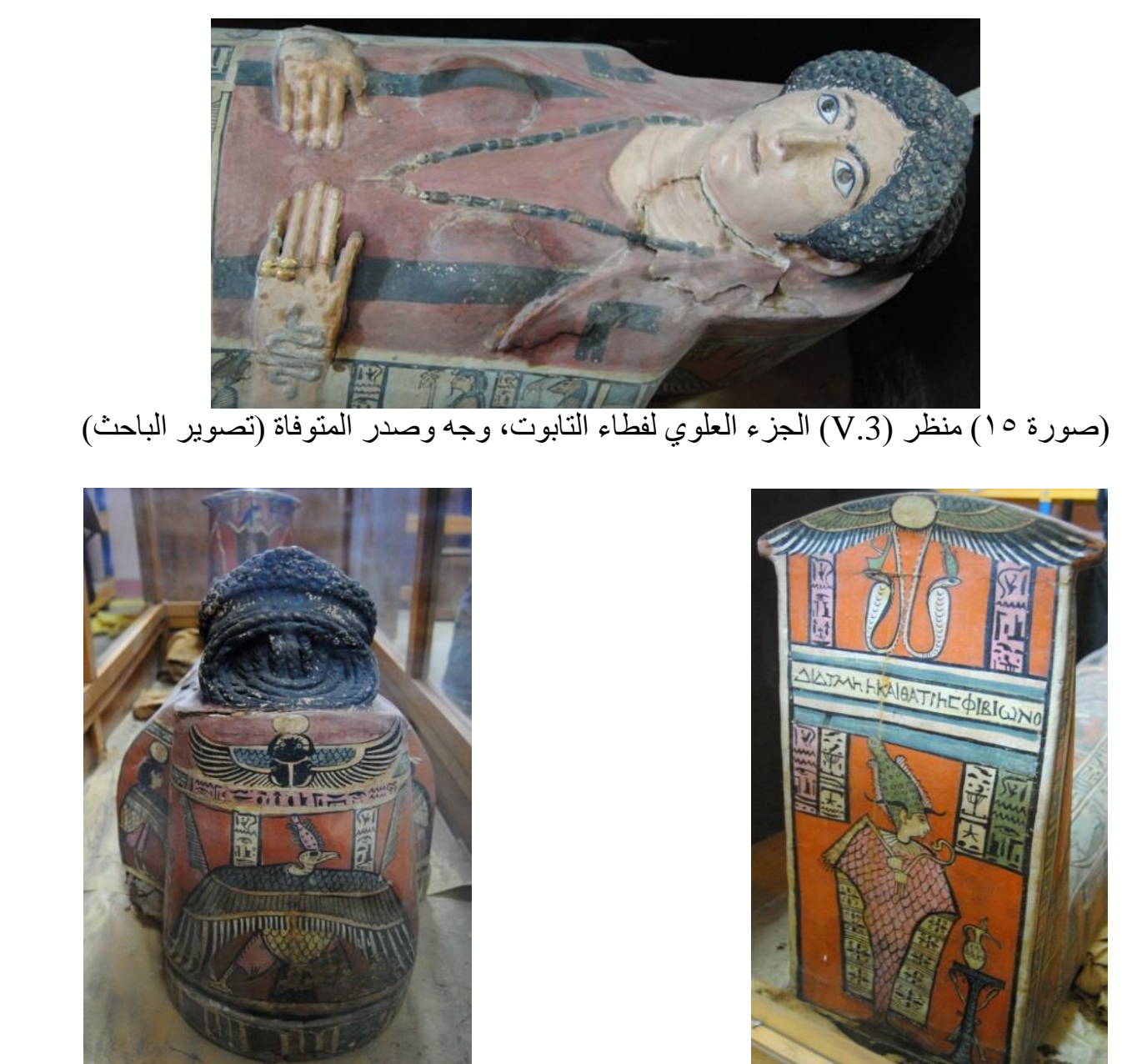

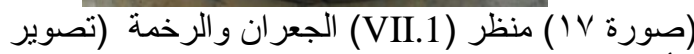

خلف رأس المنوفاة (تصوير الباحث)
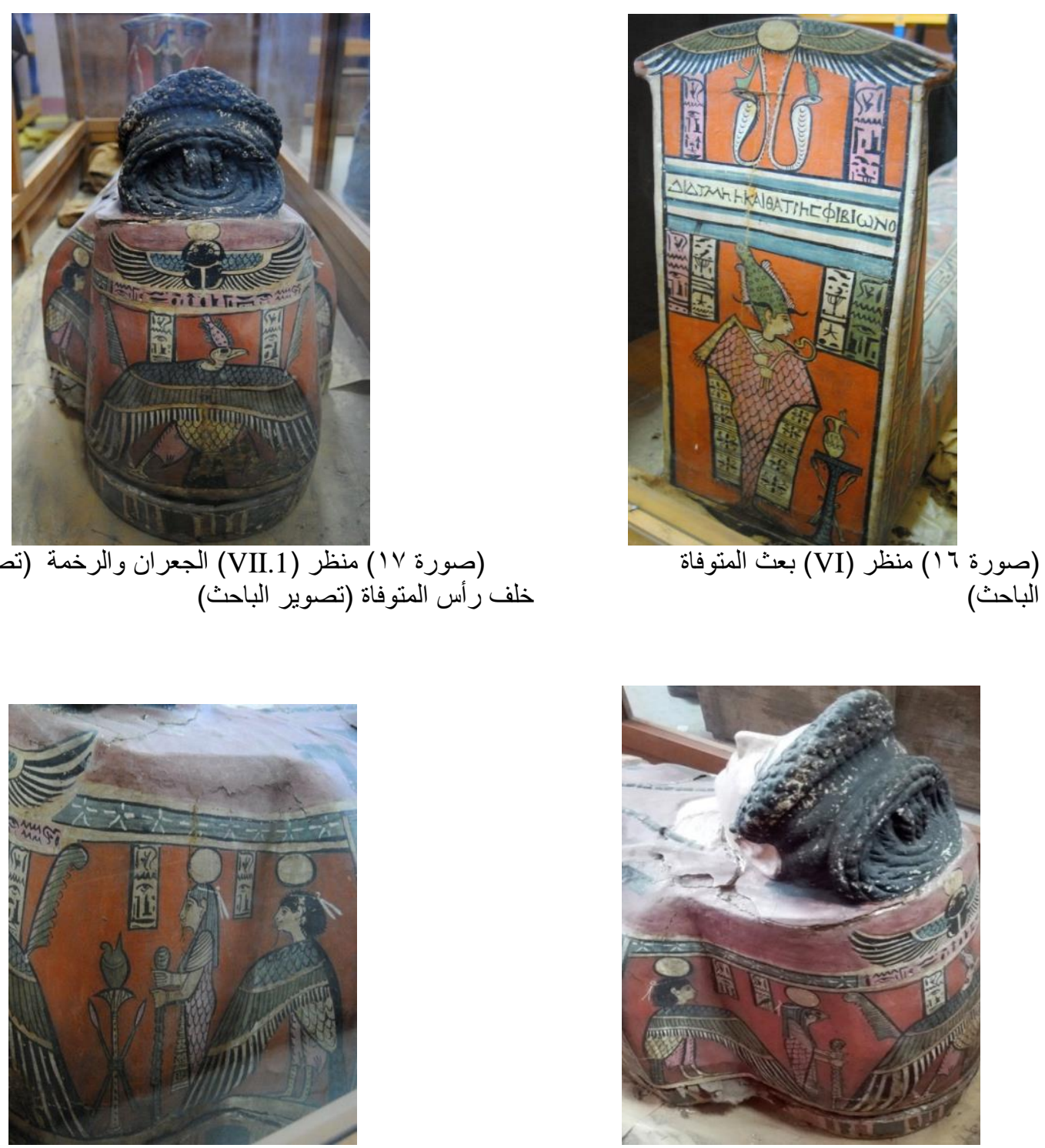

(صورة 1) ـ 1 (1) على اليمين منظر (VII.2) طائر الباوقبح سنو اف، وعلى اليسار منظر (VII.3) طائر البا وأمستي

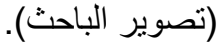




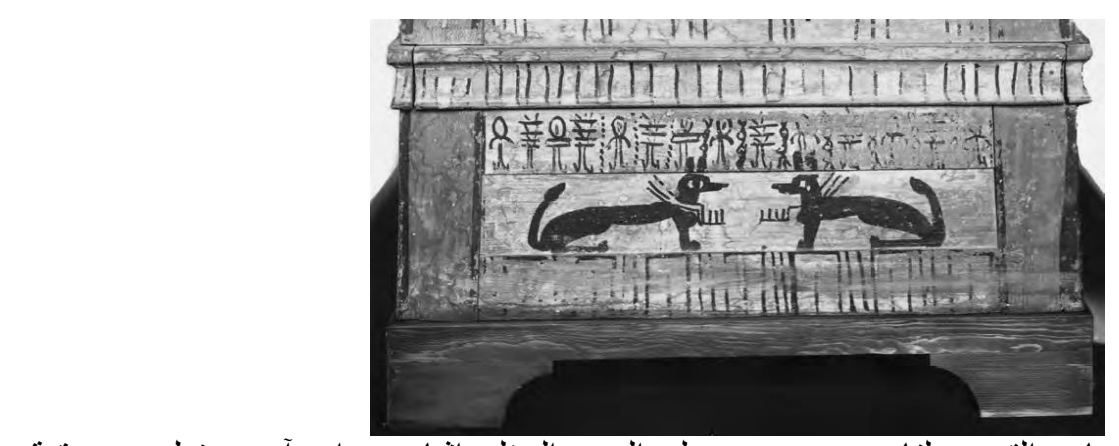

(صورة • r) منظر من الجانب القصير لتابوت ، مصور على الجزء السفلي اثنان من ابن آوى، يندلي من رقبة

كل منهما مفتاح العالم السفلي نقلاً عن:. Parlasca. K, (2010), p.225, fig.

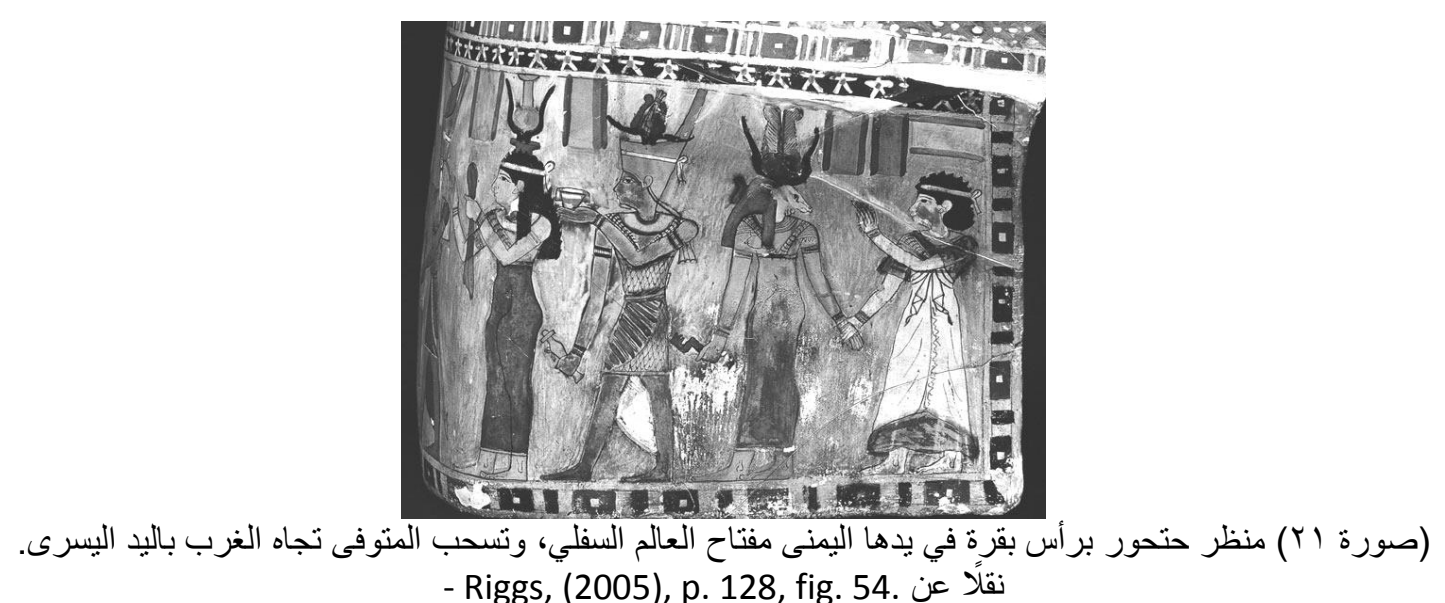

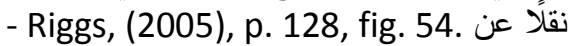

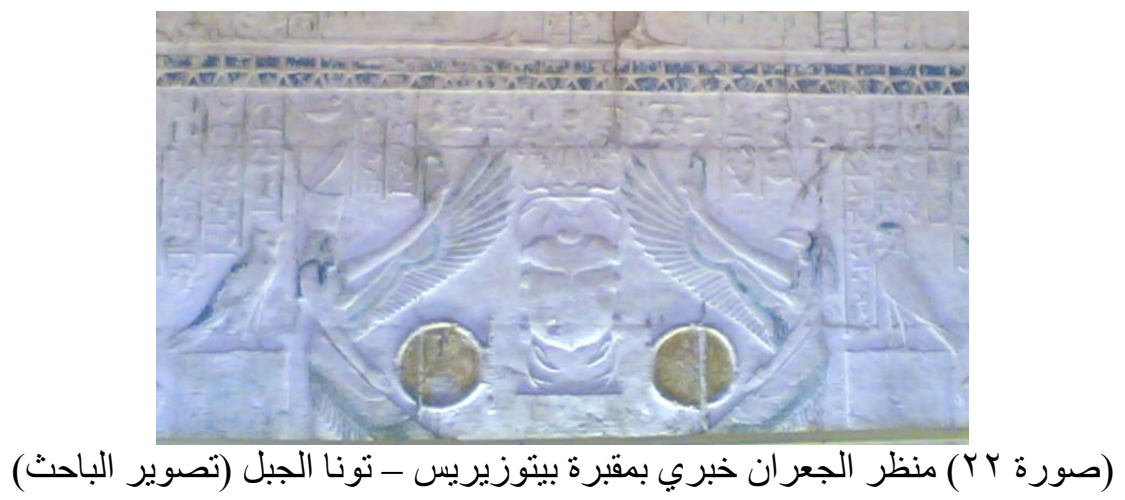




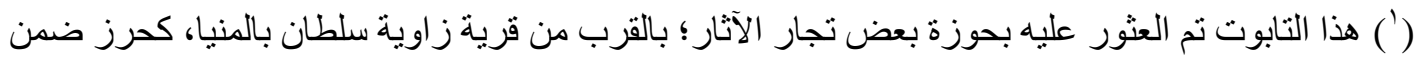

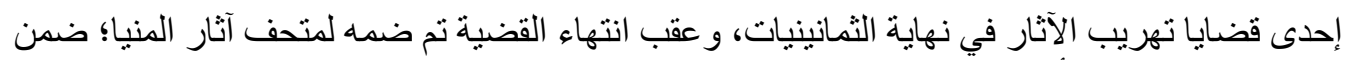

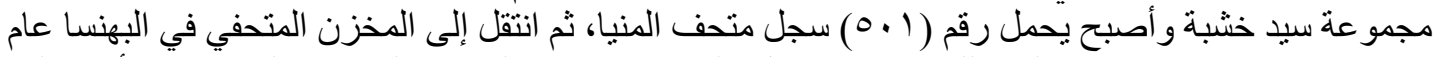

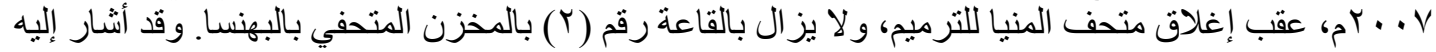
Kurth

${ }^{(2)}$ Kurth, (1990), Der Sarg der Teüris: Eine Studie zum Totenglauben im römerzeitlichen Ägypten, Aegyptiaca Treverensia 6, (Mainz Am Rhein), p. 34.

(3) Teeter, E., (2011). Religion and Ritual in Ancient Egypt, (Cambridge University Press), pp. 58-59.

4) Riggs, C., (2005), The Beautiful Burial in Roman Egypt, (Oxford), p. 34.

(5) Lefebvre. G., (1923), "Un couvercle de sarcophage de Tounah", ASAE. 23, pp. 229-245.

( ${ }^{6}$ Bergman, J., (1980), "Isis ", LÄ. III, 197.

(7) Morenz.S, (1972), 'Anubis mit dem Schlüssel', in E. Blumenthal and S. Herrmann (eds.), Religion und Geschichte Ägypten: Gesammelte Aufätze (Weimar 1972), pp.510-521, (reprinted from Wissenschaftliche Zeitschrift der Karl-Marx-Universität Leipzig. 3, (1953/4), pp.79-83.

(8) Parlasca. K, (2010), "Anubis mit dem Schlussel in der kaiserzeitlichen Grabkunst Agyptens", in : ,(ed) Bricault, L, Isis on the Nile Egyptian Gods in Hellenistic and Roman Egypt- Religions of the Greco-Roman world, vol.171,( Brill), p. 224.

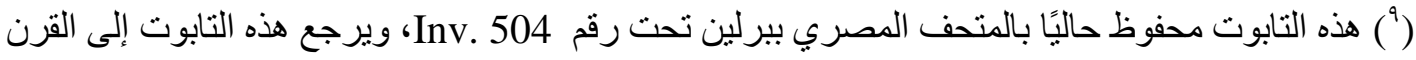

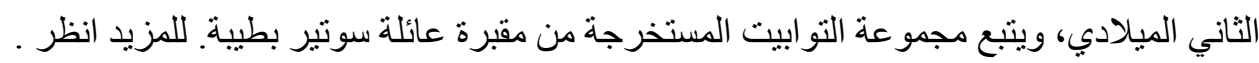

$$
\begin{aligned}
& \text { Parlasca, K., (2010), p. } 225 .
\end{aligned}
$$

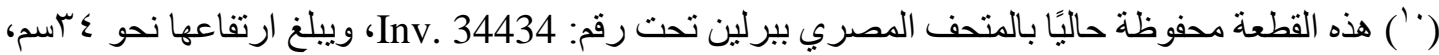

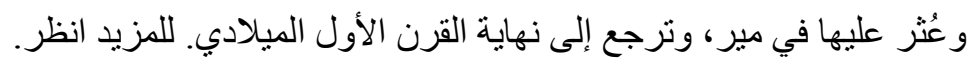

Riggs, C., (2005), p. 128.

(11) Assmann, J., (1995), Egyptian Solar Religion in the New Kingdom: Re, Amun and the Crisis of 33-56. Polytheism, (London), pp.

(12) Stadler, M.A., (2001), "Der Skarabäus als osirianisches Symbol vornehmlich nach spätzeitlichen Quellen", ZÄS. 128, ss.

(13) David. R., (1973), Religious Ritual at Abydos (London), 1973), pp. 96-98.

(14)Daumas. F., (1960), "La scène de la récurrection au tombeau de Pétosiris", BIFAO. 59, pp. 63-80.

(15) Kurth, D., (1990), p.53.

(16)Haas. N., (2008), "Hair over the Ages Hair over the Ages and in Art - The Culture, and Social History of Hair and its Depiction in Art and in Culture", in: (eds). David. A\& Ulrike. B, Hair Growth and Disorders, p. 528.

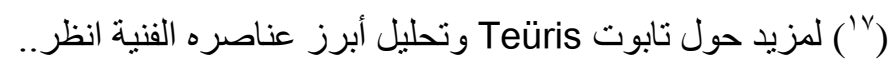

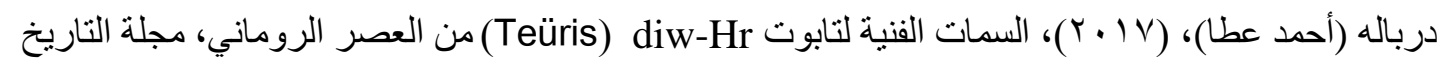

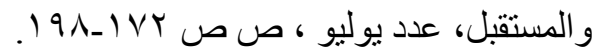

